NBER WORKING PAPER SERIES

\title{
INTERTEMPORAL PRICE DISCRIMINATION IN SEQUENTIAL QUANTITY-PRICE GAMES
}

\author{
James D. Dana Jr. \\ Kevin R. Williams \\ Working Paper 26794 \\ http://www.nber.org/papers/w26794 \\ NATIONAL BUREAU OF ECONOMIC RESEARCH \\ 1050 Massachusetts Avenue \\ Cambridge, MA 02138 \\ February 2020
}

A previous version of this paper circulated under the title "Oligopoly Price Discrimination: The Role of Inventory Controls." We would like to thank Heski Bar-Isaac, Iwan Bos, Johannes Hörner, Aniko Öry, Robert Phillips, Maher Said, Kathryn Spier, Jidong Zhou and participants at the 2016 International Industrial Organization Conference, the 2016 INFORMS Revenue Management and Pricing Conference, and the Tuck School of Business operations management workshop for helpful comments. The views expressed herein are those of the authors and do not necessarily reflect the views of the National Bureau of Economic Research.

NBER working papers are circulated for discussion and comment purposes. They have not been peer-reviewed or been subject to the review by the NBER Board of Directors that accompanies official NBER publications.

(C) 2020 by James D. Dana Jr. and Kevin R. Williams. All rights reserved. Short sections of text, not to exceed two paragraphs, may be quoted without explicit permission provided that full credit, including $\odot$ notice, is given to the source. 
Intertemporal Price Discrimination in Sequential Quantity-Price Games

James D. Dana Jr. and Kevin R. Williams

NBER Working Paper No. 26794

February 2020

JEL No. D21,D43,L0,L13

\begin{abstract}
$\underline{\text { ABSTRACT }}$
This paper develops an oligopoly model in which firms first choose capacity and then compete in prices in a series of advance-purchase markets. We show that when the elasticity of demand falls across periods, strong competitive forces prevent firms from utilizing intertemporal price discrimination. We then enrich the model by allowing firms to use inventory controls, or sales limits assigned to individual prices. We show that competing firms can profitably use inventory controls. Thus, although typically viewed as a tool to manage demand uncertainty, we show that inventory controls can also facilitate price discrimination in oligopoly.
\end{abstract}

James D. Dana Jr.

Northeastern University

301 LA, Economics Department

360 Huntington Ave.

Boston, MA 02115

j.dana@northeastern.edu

Kevin R. Williams

Yale School of Management

165 Whitney Avenue

New Haven, CT 06520

and NBER

kevin.williams@yale.edu 


\section{Introduction}

In many oligopoly markets, such as in the airline, entertainment, hotel, and sports industries, firms choose capacity long before they set price. Seminal research by Kreps and Scheinkman (1983) and Davidson and Deneckere (1986) analyzes sequential quantity-price games and characterizes when the Cournot model is a valid prediction in these sequential quantity-price games. However, an important limitation of this research is that it considers only one pricing or sales period, yet, the aforementioned industries are all clearly ones in which consumers purchase in advance and firms adjust their prices over time.

We consider an oligopoly model in which firms first choose capacity and then compete in prices in a series of advance-purchase markets. We use the model to characterize the pricing behavior of firms competing in multiple advance-purchase markets-more specifically, we explore the incentives for intertemporal price discrimination to arise in an oligopoly setting. We highlight the broad conditions under which Kreps and Scheinkman (1983) and Davidson and Deneckere (1986)'s results are unchanged by incorporating multiple sales periods.

We highlight two main contributions. First, absent additional commitments made by firms, strong competitive forces drive equilibrium prices-advance-purchase prices— to be flat over time. That is, Kreps and Scheinkman (1983) and Davidson and Deneckere (1986) are robust to breaking up sales into multiple periods because the existence of multiple sales periods creates a costless arbitrage opportunity in which a firm increases profits by shifting sales in lower-priced periods to rivals and increasing its own sales in higherpriced periods. This results in intense price competition and prevents firms from setting increasing prices when demand in later periods is more price inelastic. It also prevents firms from setting decreasing prices when demand in later periods is more elastic.

Second, we enrich the model by incorporating inventory controls, or sales limits assigned to set prices. We show that firms will choose to set inventory controls in order to engage in intertemporal price discrimination, but only if demand becomes more inelastic 
over time. Inventory controls allow for increasing prices as well as higher profits for firms, even when there is no uncertainty about demand. Thus, although inventory controls have been extensively studied in the context of demand uncertainty, we show that they can also be used for a different purpose: they can be used to facilitate price discrimination in oligopoly markets.

In our baseline model, firms sell a homogeneous good and have no private information. Firms first choose capacity levels-a capacity constraint that is common across selling periods-and then compete in price in a series of sequential markets. In each period, firms' remaining capacities are observed, and then firms simultaneously choose prices. Consumers then make their purchase decisions. After the final period, no further sales can take place and unsold inventory is worthless.

For tractability, we assume only two advance-purchase sales periods, although we do discuss extending the analysis to any finite number of periods in an extension. We assume that there are a continuum of consumers who are each assigned to one of two sequential markets, though consumers assigned to the early market can wait and purchase in the later market. We allow the elasticity of demand to change over time and emphasize the case in which demand becomes more inelastic over time, though we also establish results under the case of increasing elasticity of demand. The decreasing elasticity case is appealing for two reasons. First, it is clear that a monopolist would set increasing prices in this scenario, and second, prices tend to rise in several industries in which firms compete in sequential quantity-price setting. This includes airlines, trains, and hotels.

The challenge in solving our game, and the sequential quantity-price games studied by Kreps and Scheinkman (1983) and Davidson and Deneckere (1986), is that quantityconstrained price games often have mixed-strategy equilibrium. Solving our game is even more challenging because we consider more than one sales period. We make the analysis simpler and more intuitive by focusing on sufficiently high costs of capacity so that equilibrium capacity choices are sufficiently small and that the equilibrium strategies 
in the price game are pure strategies both on and off the equilibrium path.

Our first main result is that there exist strong competitive forces that prevent intertemporal price discrimination. Equilibrium prices are flat over time, even when consumers who arrive later have a higher willingness to pay. Equilibria with increasing prices do not exist because individual firms have an incentive to raise their price in the early period, shifting early sales to its competitors, in order to sell more in the later period, when consumers are less price-sensitive and the equilibrium price is higher. Equilibria with decreasing prices do not exist when demand becomes more elastic because consumers would wait to purchase at the lower price. However, additionally, individual firms have an incentive to lower price in the early period, shifting high-priced sales to itself and later low-priced sales to its rivals.

Because firms can costlessly shift their capacity across periods (or markets), our result may not seem surprising. But, recall that if firms could choose how much of their capacity to allocate to each market, then firms will equate the marginal revenues in the two markets, and not equate the prices. We show that with more than one pricing period, the sequential capacity-then-price game is different from the Cournot model even though it is the same as the Cournot model with just one pricing period.

We characterize sufficient conditions under which uniform prices arise as the unique pure-strategy equilibrium outcome. With a uniform price, sales are equal to the Cournot quantity associated with aggregate demand-the sum of demands over time. Although the flattening of prices occurs whether the elasticity of demand is increasing or decreasing over time, we show there exists important asymmetries in the sufficient conditions for uniform pricing in the two scenarios.

We then enrich the model by allowing firms to implement unit-sales limits, or inventory controls, in conjunction with price setting. Inventory controls have been studied extensively in the context of demand uncertainty as a means to more efficiently allocate scarce capacity (Talluri and Van Ryzin 2006, McGill and Van Ryzin 1999). We show that 
they can be used to facilitate intertemporal price discrimination. We analyze a game that differs from the baseline model in the price stage. In the game with inventory controls, firms simultaneously decide sales limits as well as prices in each of the sequential markets. We show that firms commit to the use of inventory controls in order to increase profits when the elasticity of demand decreases over time. In this case, equilibria exist in which prices are increasing because inventory controls curtail firms' abilities to shift demand to their competitors in the early, lower priced period. Firms sell their Cournot output in each period, and so prices rise over time because demand becomes less elastic. Indeed, several competitive industries, including airlines, hotels, theaters, and trains, all utilize inventory controls. $^{1}$

In summary, we identify strong competitive effects that curtail the ability of firms to price discriminate over time. Instead, firms charge a uniform price and sell the Cournot output as if sales occurred in just one period. However, when firms can use inventory controls, then as long as demand becomes more elastic over time, firms shield themselves from strong competitive effects and sell the Cournot output in each period. Prices increase over time.

We also discuss a number of extensions. One important extension is to consider product differentiation. When products are differentiated, prices are no longer uniform across time as firms benefit from the inability to shift all of the demand using very small price changes. However, the strategic incentives explored in this paper are still present. We provide an example which shows that products must be highly differentiated for prices to increase substantially across periods. Our results suggest that inventory controls are particularly valuable when products are close substitutes; they allow firms to target the market in which consumers are less price-sensitive. We also discuss extending the model to include aggregate demand uncertainty and more than two sales periods. Finally, we consider more general assumptions about inventory controls.

\footnotetext{
${ }^{1}$ Fare increases in the final weeks before departure are consistent with intertemporal price discrimination, and also consistent with theoretical models of demand uncertainty (Prescott 1975, Eden 1990, Dana 1999).
} 


\subsection{Related Literature}

This paper contributes to three strands of the economics literature.

First, we analyze a model of price competition with capacity constraints (Levitan and Shubik 1972, Allen and Hellwig 1986, Osborne and Pitchik 1986, Klemperer and Meyer 1986, Acemoglu, Bimpikis, and Ozdaglar 2009). As in Kreps and Scheinkman (1983) and Davidson and Deneckere (1986), our firms choose capacity and then price, but unlike earlier research, we consider more than one pricing period. Our results are also related to Van den Berg, Bos, Herings, and Peters (2012), who consider a two-period quantity game with capacity constraints, with and without commitment. However, our main focus is on the way firms use prices to shift rivals sales from the higher-price period to the lower-price period, which does not happen in their sequential quantity game because quantity decisions do not affect the way their rivals' capacity is allocated across periods, as prices decisions do in our model. ${ }^{2}$

Second, we analyze intertemporal price discrimination. Stokey (1979) is a seminal paper that shows that monopoly intertemporal price discrimination is not always feasible. Much of the literature on intertemporal price discrimination finds that Coasian forces constrain price discrimination (Öry 2016, Dilmé and Li 2018), however, in our setting, the key constraint on price discrimination is competition (Champsaur and Rochet 1989). Other papers consider environments with deadlines and limited capacity and find that price adjustments over time are profitable (Gallego and van Ryzin 1994, Su 2007, Möller and Watanabe 2010, Board and Skrzypacz 2016). This is particularly true when consumers learn their preferences over time, as in Akan, Ata, and Dana (2015) and Ata and Dana (2015).

Important empirical contributions to the literature on intertemporal price discrimination, and more generally price adjustments over time, include Nair (2007) on video games,

\footnotetext{
${ }^{2}$ Also see Benassy (1989) and Reynolds and Wilson (2000) for related pricing games, Aguirre (2017) for a related quantity games, and De Frutos and Fabra (2011) for a related price and capacity game.
} 
Sweeting (2012) on stadium seats, and Hendel and Nevo (2013) on storable goods. Much of our focus is on prices that increase as a deadline draws closer (such as a scheduled event or a scheduled departure time), a pattern that has been found in several airline studies (Puller, Sengupta, and Wiggins 2012, Lazarev 2013, McAfee and te Velde 2007, Williams 2018).

Finally, our work is related to the literature on inventory controls (Littlewood 1972, Belobaba 1987, Belobaba 1989, Weatherford and Bodily 1992). ${ }^{3}$ This large and important literature emphasizes that inventory controls can be an effective tool for managing aggregate demand uncertainty. Notably, our work is the first paper to establish that inventory controls can also be used to facilitate intertemporal price discrimination in oligopoly.

\section{The Model}

Consider an oligopoly with $n$ firms selling a homogeneous good to a continuum of consumers in a series of advance-purchase sales markets. For tractability, we consider just two selling periods, or stages, labeled $t=1,2$. Some consumers arrive in Stage 1 and others arrive in Stage 2. We assume that consumers who arrive earlier can buy in either Stage 1 or Stage 2, while consumer who arrive later can only purchase in Stage $2 .{ }^{4}$

We represent preferences using market demand functions, denoted by $D_{1}(p)$ and $D_{2}(p)$ respectively, which we assume are strictly decreasing and differentiable functions. We let $P_{1}(q)$ and $P_{2}(q)$ denote the inverse demands associated with $D_{1}(p)$ and $D_{2}(p)$. Note that throughout the paper we use $p_{t}^{i}$ to denote Firm $i$ 's price; we use $\mathbf{p}_{t}$ to denote the vector of all firms' prices; and we use $p_{2}$ to denote the Stage 2 price when all Stage 2 transactions are at the same price.

We let $D_{\text {tot }}(p)=D_{1}(p)+D_{2}(p)$ denote the total demand when prices are the same in both

\footnotetext{
${ }^{3}$ Talluri and Van Ryzin (2006) and McGill and Van Ryzin (1999) provide an overview of research on inventory controls.

${ }^{4}$ Alternatively, following Dana (1998) and Akan, Ata, and Dana (2015), we could have assumed that some consumers do not learn their demands until Stage 2 and then make additional mild assumptions that imply that these consumers would never want to purchase in Stage 1 even if they were able to.
} 
periods (or when Stage 1 consumers wait and purchase in Stage 2), and $P_{\text {tot }}(q)$ denote the associated inverse total demand when $q$ units of total output are sold at a uniform price. We also assume that the market demand functions are associated with concave revenue functions. That is, we assume $P_{t}^{\prime \prime}\left(q_{t}\right) q_{t}+2 P_{t}^{\prime}\left(q_{t}\right)<0, \forall t=1,2$, where $q_{t}$ denotes total sales in Stage $t$. We let $\eta_{t}(p)=D_{t}^{\prime}(p) p / D_{t}(p)$ denote the price elasticity of demand in Stage $t$.

Each firm's strategy consist of three choices, capacity and two prices, denoted by $K^{i}$, $p_{1}^{i}$, and $p_{2}^{i}$, where subscripts denote time, and, when necessary, superscripts denote the individual firm. The game proceeds in three stages (see Figure 1). First, in Stage 0, firms simultaneously choose their capacities, $K^{i} \geq 0$. The vector of initial capacities is denoted by $\mathbf{K}$. The cost per unit of capacity for all firms is $c \geq 0$. We assume that the marginal cost of production for each unit sold is zero. Then, in Stage 1, firms simultaneously choose prices denoted by the vector $\mathbf{p}_{1}$. Consumers who arrive in Stage 1 then make their purchase decisions. Sales, $\mathbf{q}_{1} \geq \mathbf{0}$, are constrained only by the firms' first period capacities, $\mathbf{K}_{1}=\mathbf{K}$, and firms' residual capacities, $\mathbf{K}_{2}=\mathbf{K}-\mathbf{q}_{1} \geq \mathbf{0}$, are carried forward to the next period. That is, capacity can be sold in either period, and the capacity constraint is common across periods. In Stage 2, firms simultaneously choose prices, denoted by the vector $\mathbf{p}_{2}$, and then consumers who arrive in Stage 2 (or waited) make their purchase decisions. Sales, $\mathbf{q}_{2} \geq \mathbf{0}$, are constrained only by the firms' residual capacities, $\mathbf{K}_{2}$. Capacity not used in Stage $2, \mathbf{K}_{2}-\mathbf{q}_{2}$, has zero value (it is scrapped at no cost). We ignore discounting.

We now describe how Firm $i$ 's individual demand is derived from these market demand functions, given the prices and capacities of the other firms. Products are homogeneous, so consumers purchase at the lowest price available, as long as their valuation exceeds the price. If firms set different prices, then a firm with a higher price can have positive sales only if all of the firms with lower prices have sold all of their capacity. If two or more firms charge the same price, then those firms divide the sales equally, subject to their capacity constraints. That is, demand is divided equally among these equally-priced firms until the firm with the least capacity sells out, and then it is divided equally among 


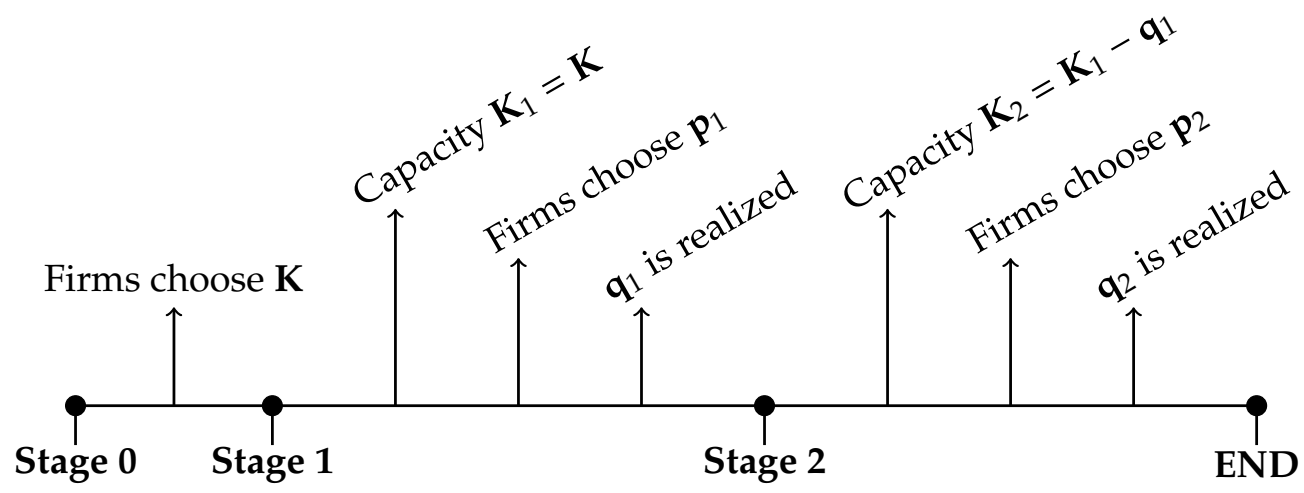

Figure 1: Timing of the Game

the remaining firms until the firm with the least capacity sells out, and so on.

How much the firm with the higher price sells-that is, the residual demand that is left after the lower priced firm sells all of its capacity-depends on the rationing rule. The residual demand function is written $R D_{t}\left(p_{t}^{i} ; \mathbf{p}_{t}^{-i}, \mathbf{K}_{t}^{-i}\right)$, where the arguments are Firm $i^{\prime} \mathbf{s}$ own price, $p_{t}^{i}$, and vectors of all of the other firms' prices and current capacities, denoted $\mathbf{p}_{t}^{-i}$ and $\mathbf{K}_{t}^{-i}$, respectively. This is the total residual demand at price $p_{t}^{i}$, which is split among all firms charging $p_{t}^{i}$.

Our results hold for both the efficient rationing rule and the proportional rationing rule. The efficient rationing rule specifies that the lowest price unit for sale (after other lower priced units are gone) goes to the remaining consumer with the highest willingness to pay. Equivalently, under the efficient rationing rule, the residual demand function is

$$
R D_{t}\left(p_{t}^{i} ; \mathbf{p}_{t}^{-i}, \mathbf{K}_{t}^{-i}\right)=D_{t}\left(p_{t}^{i}\right)-\sum_{j: p_{t}^{j}<p_{t}^{i}} K_{t^{j}}, \forall t=1,2,
$$

where the summation is over all firms $j$ that charge a lower price that Firm $i$, and where $-i$ denotes all other firms.

The proportional rationing rule specifies that lowest price unit for sale (after all other lower priced units are gone) is equally likely to be sold to every remaining consumer whose 
willingness to pay exceeds the price. Equivalently, under the proportional rationing rule, the residual demand function is

$$
R D_{t}\left(p_{t}^{i} ; \mathbf{p}_{t}^{-i}, \mathbf{K}_{t}^{-i}\right)=D_{t}\left(p_{t}^{i}\right)\left[1-\sum_{j: p^{j}<p^{i}} \frac{K_{t}^{j}}{D_{t}\left(p_{t}^{j}\right)}\right], \forall t=1,2
$$

In both cases, the residual demand describes demand at the price $p_{t}^{i}$. If only Firm $i$ charges the price $p_{t}^{i}$, then the Firm $i$ 's demand at $p_{t}^{i}$ is given by the residual demand function, and its sales are the smaller of the residual demand and its capacity. If more than one firm charges $p_{t}^{i}$, then the residual demand is divided equally among those firms, subject to each firm's capacity constraint.

Note that the rationing rules determine how sales are allocated to different firms within each period, but not how sales are allocated across periods. If consumers who arrive early have higher valuations, then it is natural to think that rationing is efficient and that demand becomes more elastic over time. Similarly, when demand is less elastic in Stage 2, then proportional rationing may be more compelling. However, we do not assume a link between rationing rules and the change in the demand elasticity. Instead, we derive results that are independent of the rationing rule, but do depend on whether demand becomes more or less elastic over time.

If there were just one pricing period, and the game ended at the end of Stage 1, then we know from Kreps and Scheinkman (1983), who analyze efficient rationing, and Davidson and Deneckere (1986), who analyze proportional rationing, that the pricing subgame has a unique Nash equilibrium. Both of these papers characterized the equilibrium profits of the pricing subgame for all capacity choices, including subgames in which the equilibrium prices were in mixed strategies. 


\section{Restriction to Pure Strategies}

Quantity-price games, including Kreps and Scheinkman (1983) and Davidson and Deneckere (1986), are known to have mixed strategy equilibrium off of the equilibrium path which makes them difficult to solve. However, both Kreps and Scheinkman (1983) and Davidson and Deneckere (1986) show that when firms choose sufficiently small capacity, then the pricing subgame has a unique pure-strategy equilibrium in which all prices equal the market-clearing price. They also show that for sufficiently high capacity costs, every pricing subgame in which firms earn positive profits has a pure-strategy equilibrium. Far from being a special case, the sufficient conditions are just that the cost of capacity is large enough so that firms never find it profitable to choose so much capacity that the marginal revenue function is negative. That is, firms collectively choose capacities smaller than the revenue maximizing capacity.

A particularly enlightening example is the case of constant elasticity demand, or $p(q)=$ $q^{1 / \epsilon}$. In this case, marginal revenue is strictly positive for all $q$ if $|\epsilon|>1$, because $p(q)+p^{\prime}(q) q=$ $(1+1 / \epsilon) q^{1 / \epsilon}$. This means that in both Kreps and Scheinkman (1983) and Davidson and Deneckere (1986)'s models, with constant elasticity demand and $|\epsilon|>1$, the equilibrium of every pricing subgame is the market-clearing price. This holds regardless of the firms' capacity choices in Stage 1. The pricing subgame never has a mixed-strategy equilibrium, so the unique equilibrium of the quantity-price game is the Cournot equilibrium. This is true regardless of the rationing rule (Madden 1998).

Because we have two pricing periods, characterizing the equilibria of the pricing subgame is considerably more challenging than in Kreps and Scheinkman (1983) and Davidson and Deneckere (1986). To simplify our analysis, we assume that capacity costs are sufficiently large so that all of the pricing subgames have pure-strategy equilibria. ${ }^{5}$

\footnotetext{
${ }^{5}$ In addition making it easy to derive the equilibrium prices and profits in all of our subgames, another benefit of assuming that capacity costs are high is that we can easily derive identical results for both the efficient and proportional rationing rules. Recall that in both Kreps and Scheinkman (1983) and Davidson and Deneckere (1986), when firms' capacities are small—specifically, smaller than the revenue maximizing
} 
We are able to restrict attention to games with pure-strategy equilibria in all of the pricing subgames by assuming that capacity costs are sufficiently large, or equivalently, Stage 0 capacity choices are sufficiently small. Specifically, we assume that

$$
\underset{q}{\operatorname{argmax}} P_{2}(q) q>\sum_{i} K^{i}
$$

Formally, we do this with two assumptions. The first is that $\operatorname{argmax}_{q} P_{2}(q) q>D_{\text {tot }}(c)$, which guarantees that marginal revenue is positive in the second pricing period, even in the event that every firm chooses not to sell any of its capacity in the first period (Assumption 1).

Assumption 1. The total competitive output with capacity costs $c$ is smaller than the capacity that maximizes industry revenue, or equivalently, smaller than the second period monopoly output when the firm has zero capacity costs. That is,

$$
\underset{q}{\operatorname{argmax}} P_{2}(q) q>D_{t o t}(c)
$$

We provide two examples to highlight the potential restrictiveness, and lack thereof, of Assumption 1.

Example 1: With constant elasticity demand, i.e., $P(q)=q^{1 / \epsilon}$ each period and $|\epsilon|>1$, a monopolist with zero cost of capacity produces an infinite output so Assumption 1 is trivially satisfied. Marginal revenue is strictly positive for all $q$, so marginal revenue is positive in Stage 2 for $q=D_{\text {tot }}(c)$, for any value $c>0$. Formally, this is because $P(q)+P^{\prime}(q) q=(1+1 / \epsilon) q^{1 / \epsilon}$, which is strictly positive for all $\epsilon<1$ and for all finite $q>0$.

Example 2: To see that Assumption 1 can be restrictive, but not unreasonably so, consider the case of linear demand, $P(q)=a-b q$, and assume that demand is the same in capacity, or equivalently smaller than a monopolist's output if capacity were free-then the price is always equal to the market-clearing price and this is independent of the rationing rule. This is because the marginal revenue is positive in the pricing stage even when firms act as a monopolist, which implies that marginal revenue must be positive individually for every firm. Thus, firms can never increase their profits by setting a price above the market-clearing price. 
both periods. Then $D_{t o t}(c)=2 \cdot((a-c) / b)$ and the monopoly output in the second period (with zero capacity costs) is $a /(2 b)$. Thus, Assumption 1 holds if, and only if, $c>(3 / 4) a$.

Although the above assumption is about the underlying parameters of the model, the second assumption that we impose places a mild and intuitive restriction on firms' strategies. We assume that the firms' total capacity does not exceed the capacity that would be produced if the market were perfectly competitive. That is, total capacity is less than $D_{\text {tot }}(c)$.

Assumption 2. Firms' capacities are less than total demand at the perfectly competitive price, or $\sum_{i} K^{i} \leq D_{\text {tot }}(c)$.

By imposing Assumption 2, we limit the firms' strategy sets to strategies that yield profits we can evaluate. Specifically, we characterize the unique equilibrium within this restricted strategy set and then show that this equilibrium is in the interior of the set, i.e., $\sum_{i} K^{i}<D_{t o t}(c)$. Although we do not formally show that every deviation outside of this set is not profitable, we do show that profits are zero and decreasing in capacity for all strategic choices on the boundary of this set.

We impose Assumption 2 in order to avoid evaluating profits in subgames with no pure strategy equilibria. This assumption, along with Assumption 1, lets us show that the Stage 2 price is always the market-clearing price, which simplifies our analysis and the intuition for our results.

Assumption 2 is difficult to relax because characterizing firms' profits and their subgame equilibrium mixed strategies in a model with two pricing periods is difficult. We believe that dropping Assumption 2 does not change the equilibria of the game, or introduce any new equilibria. That is, we believe that no equilibrium exists in which firms choose more capacity than would be chosen in a perfectly competitive market. If firms produced that much capacity and sold all of it, total profits would be negative. And it is also difficult to see how firms could benefit from such large capacity if when it is not all sold. Of course, unused capacity might be an effective off-the-equilibrium path instrument 
for punishment; however that is not the case here.

Note that there are alternatives to Assumption 2. For example, we could have instead assumed that each firm's capacity is less than $D_{\text {tot }}(c) / n$ to obtain the same result. This alternative, and others like it, are stronger and still place restrictions on firm's strategies, but this assumption does have the appealing property that the restrictions do not depend on other firms' strategic choices.

Another alternative to Assumption 2 is to assume that the Stage 0 profit function is strictly decreasing in $\mathbf{K}^{i}$ for $\mathbf{K}^{i} \geq D_{t o t}(c)-\sum_{j \neq i} \mathbf{K}^{j}$, where profit is clearly equal to 0 and locally decreasing for $\mathbf{K}^{i}=D_{t o t}(c)-\sum_{j \neq i} \mathbf{K}^{j}$. This of course is a property of the profit function normally derived from assumptions on other parameters, which we cannot do easily, but this assumption nevertheless is highly reasonable in this setting.

Together, Assumptions 1 and 2 imply that the firms' total capacity is always less than $\operatorname{argmax}_{q} p_{2}(q) q$, which implies that the firms' remaining capacity in Stage 2 is always less than $\operatorname{argmax}_{q} p_{2}(q) q$, and that the equilibrium price in the final pricing period is always the market-clearing price. This means that both on and off of the equilibrium path, every final period subgame has a unique pure-strategy equilibrium. We will maintain these assumptions throughout our analysis.

\section{A Benchmark Result}

Before characterizing the equilibrium of our game, we consider a useful benchmark. Imagine that firms set price just once, or more precisely, that firms are constrained to set the same price is Stage 2 as in Stage 1 - that is, $p_{2}^{i}=p_{1}^{i}, \forall i$. Firms choose $\mathbf{K}$ in Stage 0 and $\mathbf{p}_{1}$ in Stage 1 and the price in Stage 2 is constrained to also be $\mathbf{p}_{1}$. Then, $\mathbf{K}$ must be the symmetric Cournot output (the Cournot output when demand is $D_{1}+D_{2}$ ). This is because Assumptions 1 and 2 imply that the equilibrium price in the pricing subgame is always equal to the market clearing price, so the Stage 0 capacity game reduces to a standard Cournot model. We show this in the following lemma. All proofs, except Lemma 3, are in 
the Appendix.

Lemma 1. When firms are constrained to choose the same price in Stage 1 and Stage 2, under either the efficient or the proportional rationing rule if Assumptions 1 and 2 hold (capacity is constrained by Assumption 2), then the equilibrium price in every Stage 1 and Stage 2 pricing subgame is the market clearing price (the price such that $D_{1}(p)+D_{2}(p)=\sum_{i} K^{i}$ ) and the equilibrium capacities chosen in Stage 0 are the Cournot capacities associated with demand equal to $D_{1}(p)+D_{2}(p)$.

Since we obtain the Cournot model output levels, as the number of firms goes to infinity, the price converges to the cost of capacity, $c$, and the total capacity and sales converges to $D_{1}(c)+D_{2}(c)$. Hence, we refer to $c$ as the competitive price.

In the next section, we consider the model when firms can set different prices in each period, and when the elasticity is higher (or lower) in Stage 2 so that setting different prices generates higher profits.

\section{Equilibrium Characterization}

We now solve for the subgame perfect equilibrium of the full model, as described in Section 2, starting with Stage 2 and working backwards to Stage 0.

\subsection{The Final Pricing Period}

We first characterize equilibrium prices in Stage 2, the final pricing period. Lemma 2 states that in the second period, firms set prices to clear the market.

Lemma 2. Under either the efficient or the proportional rationing rule, if Assumption 1 and Assumption 2 hold, then in any subgame perfect equilibrium (SPE) of the three-stage game, the price in the second selling period clears the market.

Lemma 2 is important because it allows us to easily characterize all of the pure-strategy subgame-perfect equilibria of the pricing subgame. And note that it holds even if only 
one firm remains, because that firm has sunk its capacity costs and because capacity costs are large enough (by Assumption 1) that the firm wants to sell all of its capacity.

Also, note that we refer to an equilibrium as unique when all of the equilibria have the same outcomes and payoffs for all players. This is particularly important to remember because if prices decline over time, but every consumer buys in the last period, we will say this is a uniform-price equilibrium because payoffs are the same as the uniform-price equilibrium which exhibits constant prices over time and across firms.

Lemma 2 shows that the unique equilibrium of the second stage subgame is a uniform price (for firms with positive capacity), so no equilibria exist in which firms play mixed strategies in Stage 2.

\subsection{The Absence of Price Discrimination in Symmetric Equilibria}

Lemma 3 highlights why competing firms find it difficult to price discriminate over time. It highlights the competitive force that tends to equalize prices.

Lemma 3. No symmetric equilibrium of the pricing subgame exists in which prices are different in the two periods. Equivalently, in any symmetric equilibrium, $p_{1}^{i}=p_{2}^{i}, \forall i=1, \ldots, n$.

Proof. If $p_{1}^{i}<p_{2}^{i}$, and all of the firms charge the same price $\left(p_{1}^{i}=p_{1}^{j}\right.$ and $\left.p_{2}^{i}=p_{2}^{j}\right)$, then any firm could profitably deviate to a slightly higher price in Stage 1. The deviating firm's Stage 1 sales would fall discretely (possibly to zero); its Stage 2 sales would rise discretely; and the transaction price in Stage 2 would change by an arbitrarily small amount. So the deviating firm's profits would be strictly higher.

A similar argument can be made if $p_{1}^{i}>p_{2}^{i}$, and all of the firms charge the same price. In that any firm could profitably deviate to a slightly lower price in Stage 1 . The deviating firm's period 1 sales would rise discretely (possibly rise to its capacity); its Stage 2 sales would fall discretely; and the transaction prices in both periods would change by an arbitrarily small amount. So the deviating firm's profits would be strictly higher. 
However, clearly $p_{1}^{i}>p_{2}^{i}$ is also not feasible in a symmetric equilibrium because all of the consumers would wait to purchase until Stage 2 and buy at the market clearing price, which will necessarily be lower than $p_{1}^{i}$.

Lemma 3 demonstrates the strong competitive forces in the model. If prices changed over time (in a symmetric equilibrium), individual firms could change their prices in order to increase their sales in the higher-priced period. Prices cannot rise over time because firms can raise their Stage 1 price to shift sales to rivals in Stage 1 and therefore sell more in Stage 2. Lemma 3 also means price cannot fall over time, but even a monopolist cannot benefit from declining prices, because in our model consumers can wait until prices are lower in Stage 2 to make their purchases. As we now show, this does not mean that prices must be uniform.

Next, we characterize pure-strategy equilibria of the Stage 1 and Stage 2 pricing subgame. We consider the increasing and decreasing elasticity of demand cases separately.

\subsection{Decreasing Elasticity of Demand}

\subsubsection{The Pricing Subgame}

Proposition 1, below, shows that there are two types of pure-strategy subgame perfect equilibria in the pricing subgame when the elasticity of demand decreases over time. In a uniform-price equilibrium, transaction prices are the same for all firms and all consumers as well as across the two pricing periods. Since the market clears in Stage 2 (see Lemma 2 above), any uniform-price equilibrium must satisfy $D_{1}\left(p^{*}\right)+D_{2}\left(p^{*}\right)=\sum_{i} K^{i}$, so the uniform price is unique (as in Lemma 1). Note that because all Stage 1 consumers can wait and purchase in Stage 2, a uniform-price equilibrium with declining offer prices may exist, but transactions prices are uniform.

In an asymmetric-price equilibrium, a single firm sells in Stage 1; the Stage 1 price is lower than the Stage 2 price; and all other firms sell only in Stage 2. Let Firm $i$ be the firm 
that sells in the first period, and let $p_{1}^{i}$ and $q_{1}^{i}$ denote its first-period price and quantity, where

$$
p_{1}^{i}=\underset{p \in\left[P_{1}\left(K^{i}\right), \infty\right]}{\operatorname{argmax}} p D_{1}(p)+P_{2}\left(\sum_{i} K^{i}-D_{1}(p)\right)\left(K^{i}-D_{1}(p)\right),
$$

or, equivalently,

$$
q_{1}^{i}=\underset{q \in\left[0, K^{i}\right]}{\operatorname{argmax}} P_{1}(q) q+P_{2}\left(\sum_{i} K^{i}-q\right)\left(K^{i}-q\right) .
$$

In both expressions, Firm $i$ 's first-period sales do not exceed $K^{i}$. The second-period price is higher than $p_{1}^{i}$ and is given by

$$
P_{2}\left(\sum_{i} K^{i}-D_{1}\left(p_{1}^{i}\right)\right)
$$

Note, however, that Proposition 1 holds regardless of whether the elasticity is increasing or decreasing.

Proposition 1. Under either the efficient or the proportional rationing rule, if Assumptions 1 and 2 hold, then every pure-strategy subgame-perfect equilibrium of the pricing subgame is either a uniform-price equilibrium or an asymmetric-price equilibrium satisfying Equations (3), (4) and (5). When a uniform-price equilibrium exists, it is the unique pure-strategy subgame-perfect equilibrium.either a uniform-price equilibrium exists, or uniform-price equilibrium does not exist and between one and $n$ asymmetric-price equilibria exist.

Intuitively, asymmetric-price equilibria exist because a lower price in Stage 1 increases sales in the Stage 1, leading to less output sold and a higher price in Stage 2. But a firm can increase its profit in this way only if the elasticity is decreasing (so increasing prices is desirable) and only if it has sufficient capacity to meet all of the demand in Stage 1 plus enough additional capacity to profit from selling at the higher price in Stage 2. Other firms free ride and sell only in Stage 2 at the higher price. 
Asymmetric-price equilibria are more likely to exist when one firm chooses more capacity than its rivals in Stage 0. The uniform-price equilibrium is less likely to exist when one firm chooses significantly more capacity than its rivals. The incentive to deviate to a lower price is increasing in the deviating firm's capacity, decreasing in the rival firms' capacity, increasing in the elasticity of first-period demand, and decreasing in the size of Stage 1 demand.

Proposition 1 suggests that whether the demand elasticity is increasing or decreasing, price competition puts pressure on firms to equalize prices across the two markets. That is, equilibrium prices are either uniform, or, if one firm is sufficiently large, the large firm unilaterally implements an asymmetric-price equilibrium. And although Proposition 1 shows that asymmetric-price equilibria of the pricing subgame may exist, we can now show that under relatively mild additional assumptions, the unique equilibrium is a uniform-price equilibrium even when the elasticity of demand is decreasing. Assumption 3, stated below, is a sufficient condition to guarantee that asymmetric-price equilibria do not exist.

Assumption 3 requires that demand in Stage 2 not be too inelastic relative to demand in Stage 1. While demand in the Stage 2 is less elastic than demand in Stage 1, Assumption 3 limits how inelastic demand in Stage 2 can be. This relatively weak assumption implies that no firm has enough capacity to profitably deviate from the symmetric uniform-price equilibrium.

Assumption 3. The elasticities of demand and capacities satisfy

$$
\frac{\eta_{2}(p)}{\eta_{1}(p)}>\frac{K^{i}}{\sum_{j=1}^{n} K^{j}}, \forall p>0, i=1, \ldots, n
$$

Proposition 2. When the elasticity of demand is decreasing over time, or $\left|\eta_{1}(p)\right|>\left|\eta_{2}(p)\right|, \forall p>0$, then under Assumptions 1, 2, and 3, the unique subgame-perfect pure-strategy equilibrium of the Stage 1 and Stage 2 pricing subgame is a uniform-price equilibrium. 
Intuitively, when the elasticity is decreasing, deviating to a lower price from a uniform price is profitable for a monopolist if it raises the Stage 2 profit by more than it lowers the Stage 1 profit. However, since rivals free ride and sell only in Stage 2, an oligopoly firm that deviates from a uniform price, by lowering its Stage 1 price, earns at most $1 / n$th of the Stage 2 industry profits. The oligopoly firm that deviates cannot increase its profit unless it can increase the Stage 2 industry profits by at least $n$ times the decrease in its Stage 1 profit. For such a deviation to be profitable, the Stage 1 demand must be at least $n$ times more elastic than the Stage 2 demand. Assumption 3 guarantees that such a deviation is not profitable.

Proposition 2 is an important result. It shows that oligopoly firms are unable to price discriminate even when a monopolist would clearly price discriminate under these conditions. ${ }^{6}$ The unique subgame-perfect pure-strategy equilibrium of the Stage 1 and Stage 2 pricing subgame is a uniform-price equilibrium.

\subsubsection{Initial Capacity Choice}

We now consider the full game, including the initial capacity choice. We replace Assumption 3 with Assumption 4, which is weaker. It is equivalent to Assumption 3 when the firms' capacities are symmetric. Proposition 3 establishes that Assumption 4 is sufficient to guarantee that when firms choose their capacities in Stage 0, the unique subgame perfect equilibrium is still a uniform-price equilibrium.

Assumption 4. The elasticity of demand satisfies

$$
\frac{\eta_{2}(p)}{\eta_{1}(p)}>\frac{1}{n}, \forall p>0
$$

\footnotetext{
${ }^{6}$ We also conclude prices are uniform when the elasticity of demand is increasing, but that is a setting in which a monopolist would also set uniform prices because consumers can postpone their purchases in our model.
} 
Proposition 3. If the elasticity of demand is decreasing, then under Assumptions 1, 2 and 4 the unique pure-strategy subgame perfect Nash equilibrium of the full game is a uniform-price equilibrium, and equilibrium capacity and profits are equal to the Cournot capacity and profits given demand $D_{1}(p)+D_{2}(p)$.

Proposition 3 implies that except in more extreme cases (i.e., when Assumption 4 is violated) intertemporal price discrimination is impossible when demand becomes more inelastic over time.

\subsection{Increasing Elasticity of Demand}

We now establish results under the case in which the elasticity of demand is increasing over time. Note that when the elasticity of demand is increasing over time, consumers have an incentive to wait to purchase. These Coasian forces can prevent even a monopolist from using intertemporal price discrimination.

The following proposition establishes that prices are always uniform in the pricing subgame when the elasticity of demand is increasing.

Proposition 4. When the elasticity of demand is constant or increasing, $\left|\eta_{1}(p)\right| \leq\left|\eta_{2}(p)\right|, \forall p>0$, then under either the efficient or the proportional rationing rule, if Assumptions 1 and 2 hold, then the unique pure-strategy subgame-perfect equilibrium of the pricing subgame is a uniform-price equilibrium.

This result holds for two reasons. First, the same competitive forces that constrain firms when the elasticity of demand is increasing-firms want to shift lower priced sales onto their rivals - constrain firms when the elasticity of demand is decreasing. Second, and more importantly, prices are constrained by the fact that consumers can wait and purchase in Stage 2 if prices decline over time. 


\subsubsection{Initial Capacity Choice}

Proposition 5. When the elasticity of demand is increasing, $\left|\eta_{1}(p)\right| \leq\left|\eta_{2}(p)\right|, \forall p>0$, then under Assumptions 1 and 2 the unique pure-strategy subgame perfect Nash equilibrium of the full game is a uniform-price equilibrium and equilibrium capacity and profits are equal to the Cournot capacity and profits given demand $D_{1}(p)+D_{2}(p)$.

Proposition 5 is trivial to establish given all the previous results. When the elasticity of demand is increasing, Assumption 4 is always satisfied. Hence, we do not need any additional assumptions-when the elasticity of demand is increasing, the Cournot model is even more robust to breaking up demand into multiple pricing periods. However, this is largely because consumers have the option to wait. ${ }^{7}$

\section{Inventory Controls}

In the previous section, we showed that firms typically produce the same Cournot capacity and set the Cournot price in both periods, as if there were just one period with demand $D_{1}(p)+D_{2}(p)$. This is true even though profits would be higher if firms use intertemporal price discriminate.

We now show that inventory controls make it possible for firms to price discriminate and earn higher profits, but only if demand becomes more inelastic over time. We model inventory controls as an upper bound on quantities sold, and we allow firms to set inventory controls when they set their price. That is, firms first choose their initial capacity, and then, in each of the two subsequent periods, simultaneously choose both their price and an inventory control. The game is shown in Figure 2.

Inventory controls allow firms to limit the number of units available so that its availability exactly matches the number of units it expects to sell in period one. Thus, by

\footnotetext{
${ }^{7}$ In an earlier version of the paper, we assumed that consumers did not have the option to wait and we showed that a pure-strategy equilibrium might not exist under increasing elasticity of demand.
} 


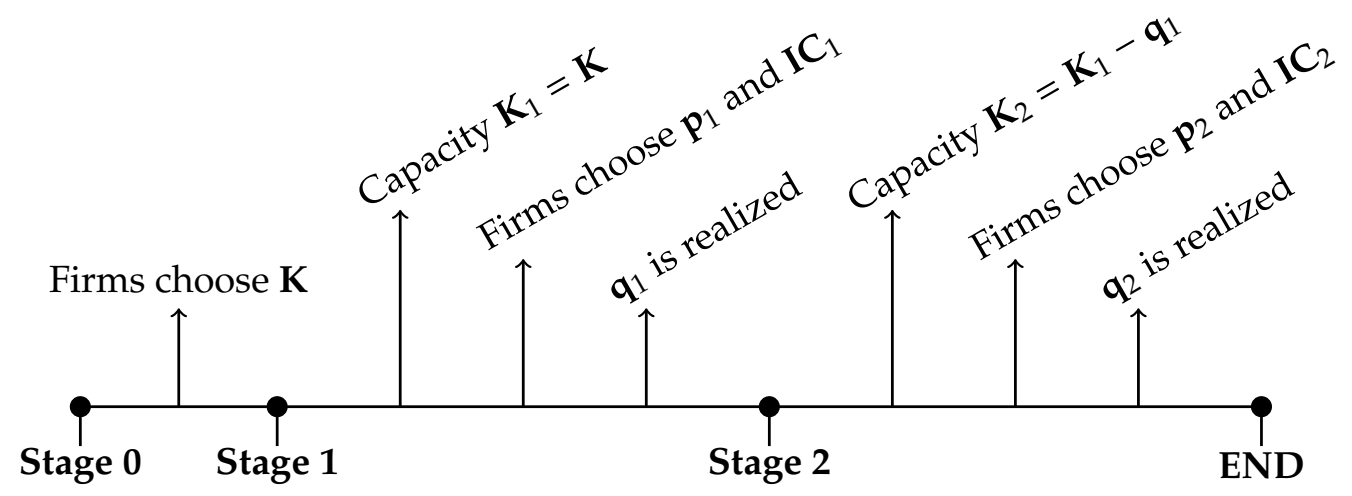

Figure 2: Timing of the Game with Inventory Controls

utilizing inventory controls, firms can ensure that if a rival deviates to a higher price in Stage 1, their own sales will not increase.

The logic above only holds when demand becomes more inelastic over time because inventory controls place a cap on sales and not a floor. Thus, inventory controls highlight another natural asymmetry that arises between increasing and decreasing elasticity of demand: Inventory controls can prevent a rival from increasing a firm's sales by deviating to a higher price, but they cannot prevent a rival from lowering a firm's sales by deviating to a lower price.

Proposition 6. When the elasticity of demand is decreasing, then under Assumptions 1, 2 and 4, and under either the efficient or the proportional rationing rule, a subgame perfect Nash equilibrium of the model with inventory controls exists in which all firms set the Cournot price and set inventory controls equal to the Cournot quantity in each selling period. Profits are strictly higher in this equilibrium than in the uniform-price equilibrium.

In the equilibrium described in the above proposition, firms commit to inventory controls which are equal to each firm's equilibrium sales in each period. Inventory controls do not restrict output on the equilibrium path, but they do act as a strategic commitment device because they constrain the firm's off-the-equilibrium-path output. In the equilib- 
rium, firms sell their Cournot output in each period, and so prices rise over time because demand becomes less elastic. Without inventory controls, firms set a constant price across the two periods and sales are equal to the Cournot quantity associated with the aggregate demand, $D_{1}(p)+D_{2}(p)$. In the equilibrium with inventory controls, firms set prices equal to the Cournot quantities in each period, that is, the Cournot output associated with demand $D_{1}\left(p_{1}\right)$ in Stage 1 and the Cournot output associated with demand $D_{2}\left(p_{2}\right)$ in Stage 2.

The model with inventory controls does have other equilibria. In particular, the symmetric capacity, uniform-price equilibrium characterized in Proposition 3 may still be a subgame perfect equilibrium of the inventory control game. Even when it is not, there are many different increasing price paths that can be supported with inventory controls. We think that it is natural for firms to coordinate on the Cournot quantities, but the point is that they can price discriminate and earn higher profits using inventory controls.

Example: We illustrate the impact of inventory controls on prices and profits in an example with linear demand, $P_{t}\left(q_{t}\right)=a_{t}-b_{t} q_{t}$, and constant cost per unit of capacity, $c$. Suppose that the firms could choose capacity independently for each period (as if the two periods were separate markets). Then the Cournot profits with price discrimination are given by

$$
\Pi_{\text {discr. }}=\frac{\left(b_{2}\left(a_{1}-c\right)^{2}+b_{1}\left(a_{2}-c\right)^{2}\right)}{\left(b_{1} b_{2}(n+1)^{2}\right)}
$$

and the Cournot profits with uniform pricing are

$$
\Pi_{\text {uniform }}=\frac{\left(b_{2}\left(a_{1}-c\right)+b_{1}\left(a_{2}-c\right)\right)\left(\frac{b_{2} a_{1}+b_{1} a_{2}}{b_{1}+b_{2}}-c\right)}{\left(b_{1} b_{2}(n+1)^{2}\right)} .
$$


And profits are higher with discrimination (see the Appendix for more details),

$$
\begin{aligned}
\Pi_{\text {discr. }}-\Pi_{\text {uniform }} & =b_{2}\left(a_{1}-c\right)^{2}+b_{1}\left(a_{2}-c\right)^{2}-\left(b_{2}\left(a_{1}-c\right)+b_{1}\left(a_{2}-c\right)\right)\left(\frac{b_{2} a_{1}+b_{1} a_{2}}{b_{1}+b_{2}}-c\right) \\
& =\frac{1}{b_{1}+b_{2}}\left(b_{2}\left(a_{1}-c\right)\left(b_{1}\left(a_{1}-a_{2}\right)+b_{1}\left(a_{2}-c\right) b_{2}\left(a_{2}-a_{1}\right)\right)\right. \\
& =\frac{b_{1} b_{2}}{b_{1}+b_{2}}\left(\left(a_{1}-c\right)\left(a_{1}-a_{2}\right)+\left(a_{2}-c\right)\left(a_{2}-a_{1}\right)\right)=\frac{b_{1} b_{2}}{b_{1}+b_{2}}\left(a_{1}-a_{2}\right)^{2}>0 .
\end{aligned}
$$

\section{Model Extensions}

\subsection{Alternative Timing of Inventory Controls}

Inventory controls could also be modeled other ways, including allowing firms to commit to inventory controls before setting price. If firms could commit to inventory controls before announcing prices, inventory controls serve two functions. First, they prevent rival firms from raising their price in order to increase our sales when the price is low. And second, they limit our own sales in Stage 1. The latter is important and impacts equilibrium strategies, but collectively firms want to set increasing prices and sell more in Stage 1 than they do in the uniform-price equilibrium, so commitment does not help firms to unilaterally increase profits in obvious ways.

If firms could announce and commit to their inventory controls each period before any firm sets price, then Proposition 4 still holds. In this case, if each firm sets an inventory control equal to the Cournot output, this would result in the Cournot prices, and no unilateral inventory control deviation would effect the subsequent prices. But this timing may also eliminate the uniform price equilibrium. In a duopoly model, a unilateral inventory control would curtail the rival's incentives to raise price and cause the rival to equate marginal revenue across the two periods, even when the rival hadn't set an inventory control itself. 


\subsection{Product Differentiation}

Differentiation does not alter firms' incentive to attempt to shift demand to competitors in the early period. However, product differentiation makes it more costly to shift demand. With undifferentiated products, a small price change shifts all of the demand. With differentiated products, a firm's price increase must be larger, and have a first-order effect on its profits, in order to have a significant impact on a rival's sales.

Product differentiation also introduces increased complexity, so we focus our attention on two firms in a symmetric environment, and give intuition instead of analyzing the equilibrium of the model. We also maintain the assumption that capacity is sufficiently small so that firms always set market-clearing prices in the second period.

Figure 3: Intertemporal Price Discrimination as a Function of Product Differentiation

\section{(a) Prices Across Periods}

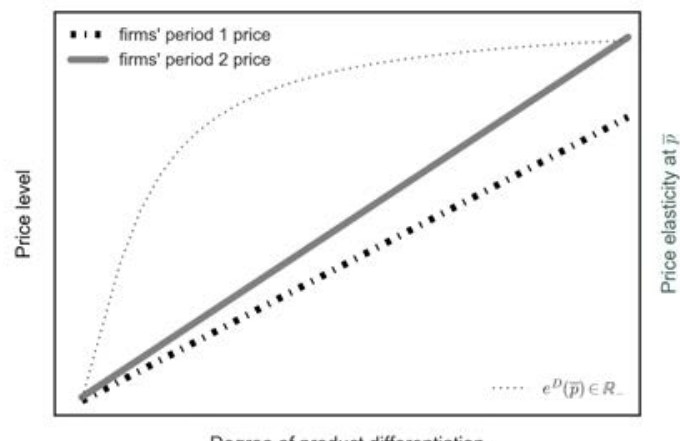

(b) Competition vs. Joint-Profit Maximization

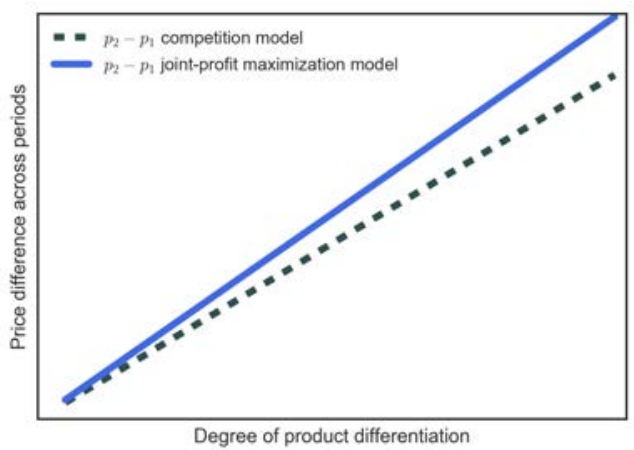

Notes: Example constructed using a random utility model (logit) with two firms and two periods. Product differentiation is increasing towards the right of the plots. (a) The light dashed line corresponds to the own-price elasticity for a constant price offered by both firms. As products become increasingly differentiated, the difference between $p_{1}$ and $p_{2}$ increases. (b) Shows the change in price $\left(p_{2}-p_{1}\right)$ of competition model versus the joint-profit maximization model. Prices are flatter in the competition model, as the gap between the two models grows with the degree of differentiation.

Product differentiation results in equilibrium subgame prices that are no longer uniform over time; however, prices are flatter-as a function of the degree of product differentiation - than joint-profit-maximizing prices (see Figure 3 for an example, where the left plot shows increasing differences in prices across periods as product differenti- 
ation increases). To see this, consider two firms, $A$ and $B$, and let the inverse demand functions be $P_{1}^{A}\left(q_{1}^{A}, q_{1}^{B}\right), P_{1}^{B}\left(q_{1}^{A}, q_{1}^{B}\right), P_{2}^{A}\left(q_{2}^{A}, q_{2}^{B}\right)$, and $P_{2}^{B}\left(q_{2}^{A}, q_{2}^{B}\right)$. Joint-profit-maximizing firms would set marginal revenue equal to the shadow cost of capacity in each of the

four product markets, so $\frac{\partial P_{i}^{j}\left(q_{t}^{j}, q_{t}^{-j}\right)}{\partial q_{t}^{j}} q_{t}^{j}+P_{t}^{j}\left(q_{t}^{j}, q_{t}^{-j}\right)=\lambda, \forall t=1,2 ; j=A, B$. Suppose that the joint-profit-maximizing prices are increasing over time.

Contrast these prices with the prices that would be set by two competing firms given the same initial capacity. If Firm $A$ sets a higher price than the joint-profit-maximizing firm, it will sell less in the first period and, hence, more in the second period. Sales for Firm $B$ are higher in the first period, and it has less to sell in the second period; thus, in the second period, its price is higher and Firm $A$ 's demand is higher. Because it ignores the loss for Firm $B$, Firm $A$ has an incentive to set a higher first-period price than the jointprofit-maximizing monopolist. Firm $B$ has a similar incentive, and, in equilibrium, both firms' prices will be flatter relative to joint-profit-maximizing prices (see the right panel in Figure 3). It is also worth noting that prices might still be perfectly flat if sufficiently many consumers were indifferent between the firms-a symmetric increasing price equilibrium does not exist because either firm could strictly increase profits with an arbitrarily small price increase.

\subsection{Aggregate Demand Uncertainty}

Inventory controls are generally described as a tool for managing demand uncertainty, so it is important to describe how the model can be extended to include such uncertainty. To generate intuition, we describe an extension in which just first-period demand is uncertain. A monopolist sets the first-period price before learning the first-period demand and sets a second-period price to clear the market.

A simple way to add uncertainty to the model is assume realized demand can be high or low in the first period, but is known to be high in the second period. In this case a monopolist choosing capacity optimally would set a lower price (based on expected 
demand) in the first period.

However, the monopoly prices are not an equilibrium with competing firms, even if the firms have the same capacity as the monopolist. Because the monopoly prices increase in expectation, competing firms prefer to sell more of their capacity in the second period, when the expected price is higher. And any firm can shift a discrete amount of its first-period sales to its rival through an arbitrarily small price increase in the first period. Thus, expected prices must be equal in the two periods in any symmetric pure-strategy equilibrium.

\subsection{Many Periods}

An obvious limitation of the paper is that we consider only two pricing periods. One challenge to extending Propositions 2 and 3 to many periods is that it requires stronger assumptions than Assumptions 1 and 2 in order to ensure firms play pure strategies for all histories of the game. Another limitation is the potential for multiple equilibria.

One way to consider many periods is to focus on a duopoly model with constant elasticity demand, but allow the demand elasticity to become more inelastic over time. Then, sufficient conditions could be derived under which the last $m$ periods have a uniform price equilibrium for all capacities. Then, going from $m$ to $m+1$ periods is similar to going from one to two periods in our previous analysis, because the $m$-period-subgame price is always the market-clearing price. The only challenge is those sufficient conditions are no longer on the initial capacities.

In particular, consider a three-period model. Here, it is possible to describe conditions under which a uniform-price is the unique outcome: on the equilibrium path, the final two pricing periods of the three-period game are equivalent to our analysis above, so prices must be equal in the final two periods as long as capacities are sufficiently equal. More importantly, the intuition that firms can profit from shifting lower-price sales to the rivals still holds, which is why sustaining increasing prices is difficult. 


\section{Conclusion}

We establish that inventory controls can facilitate intertemporal price discrimination in oligopoly. We consider an advance-purchase, sequential-pricing model with complete information. When a single firm serves the market and demand becomes more inelastic over time, the firm can clearly charge higher prices to late arriving consumers. However, in our oligopoly model, strong competitive forces arise. Individually, firms have an incentive to move their capacity to the period with a highest price. That is, firms have an incentive to shift sales to their rivals in early periods, when consumers have lower willingness to pay, in order to capture increased sales in later periods when consumers have higher willingness to pay. Consequently, we find that firms will compete on price until prices are equalized across the selling periods even though firms have market power and would earn higher profits if prices were increasing.

In order for firms to coordinate price increases when late arriving consumers have higher willingness to pay, they must shield themselves from these strong competitive forces. By committing to a cap on their sales in each of the sequential markets, which they can do with inventory controls, competing firms are able to implement increasing prices. There is extensive research in economics and operations research on the use of inventory controls as a tool to manage uncertain demand, but here we show that inventory controls are also a tool to facilitate intertemporal price discrimination.

\section{References}

Acemoglu, D., K. Bimpikis, and A. Ozdaglar (2009): “Price and Capacity Competition," Games and Economic Behavior, 66(1), 1-26.

Aguirre, I. (2017): “Cournot Oligopoly, Price Discrimination and Total Output," working paper.

Aкan, M., B. Ata, and J. D. Dana (2015): “Revenue management by sequential screening," Journal of Economic Theory, 159, 728-774. 
Allen, B., And M. Hellwig (1986): “Bertrand-Edgeworth oligopoly in large markets," The Review of Economic Studies, 53(2), 175-204.

Ata, B., And J. D. Dana (2015): “Price discrimination on booking time," International Journal of Industrial Organization, 43, 172-181.

Belobaba, P. P. (1987): “Air travel demand and airline seat inventory management," Ph.D. thesis, Massachusetts Institute of Technology.

- (1989): "OR practice-application of a probabilistic decision model to airline seat inventory control," Operations Research, 37(2), 183-197.

Benassy, J.-P. (1989): "Market size and substitutability in imperfect competition: A Bertrand-Edgeworth-Chamberlin model," The Review of Economic Studies, 56(2), 217234.

Board, S., and A. Skrzypacz (2016): “Revenue Management with Forward-Looking Buyers," Journal of Political Economy, 124(4), 1046-1087.

Champsaur, P., and J.-C. Rochet (1989): “Multiproduct duopolists," Econometrica: Journal of the Econometric Society, pp. 533-557.

Dana, J. D. (1998): “Advance-Purchase Discounts and Price Discrimination in Competitive Markets," Journal of Political Economy, 106(2), 395-422.

_ (1999): "Equilibrium Price Dispersion under Demand Uncertainty: The Roles of Costly Capacity and Market Structure," The RAND Journal of Economics, 30(4), 632-660.

Davidson, C., and R. Deneckere (1986): "Long-run competition in capacity, short-run competition in price, and the Cournot model," The RAND Journal of Economics, pp. 404-415.

De Frutos, M.-A., and N. Fabra (2011): “Endogenous capacities and price competition: The role of demand uncertainty," International Journal of Industrial Organization, 29(4), 399-411.

Dilmé, F., and F. Li (2018): “Revenue Management without Commitment: Dynamic Pricing and Periodic Flash Sales," The Review of Economic Studies, p. forthcoming.

EDEN, B. (1990): “Marginal cost pricing when spot markets are complete," Journal of Political Economy, pp. 1293-1306.

Gallego, G., and G. van Ryzin (1994): “Optimal Dynamic Pricing of Inventories with Stochastic Demand over Finite Horizons," Management Science, 40(8), 999-1020. 
Hendel, I., And A. Nevo (2013): “Intertemporal price discrimination in storable goods markets," American Economic Review, 103(7), 2722-51.

Klemperer, P., and M. Meyer (1986): “Price Competition vs. Quantity Competition: The Role of Uncertainty," The RAND Journal of Economics, 17(4), 618-638.

Kreps, D. M., and J. A. Scheinkman (1983): "Quantity precommitment and Bertrand competition yield Cournot outcomes," The Bell Journal of Economics, pp. 326-337.

LAZAREV, J. (2013): “The welfare effects of intertemporal price discrimination: an empirical analysis of airline pricing in U.S. monopoly markets," Discussion paper, New York University.

Levitan, R., And M. Shubik (1972): “Price Duopoly and Capacity Constraints," International Economic Review, 13(1), 111-122.

Littlewood, K. (1972): "Forecasting and control of passenger bookings," Airline Group International Federation of Operational Research Societies Proceedings, 1972, 12, 95-117.

Madden, P. (1998): "Elastic demand, sunk costs and the Kreps-Scheinkman extension of the Cournot model," Economic Theory, 12(1), 199-212.

McAfee, R. P., And V. te Velde (2007): “Dynamic pricing in the airline industry," Handbook on Economics and Information Systems, Ed: TJ Hendershott, Elsevier.

McGill, J. I., ANd G. J. VAn Ryzin (1999): “Revenue management: Research overview and prospects," Transportation Science, 33(2), 233-256.

Möller, M., and M. Watanabe (2010): “Advance purchase discounts versus clearance sales," The Economic Journal, 120(547), 1125-1148.

NAIR, H. (2007): "Intertemporal price discrimination with forward-looking consumers: Application to the U.S. market for console video-games," Quantitative Marketing and Economics (QME), 5(3), 239-292.

ÖRY, A. (2016): “Consumers on a Leash: Advertised Sales and Intertemporal Price Discrimination," working paper.

Osborne, M. J., and C. Рітснік (1986): "Price competition in a capacity-constrained duopoly," Journal of Economic Theory, 38(2), 238 - 260.

Prescott, E. C. (1975): "Efficiency of the natural rate," Journal of Political Economy, 83(6), 1229-1236.

Puller, S. L., A. Sengupta, and S. N. Wiggins (2012): “Does scarcity drive intra-route price dispersion in airlines?," NBER Working Paper, 15555. 
Reynolds, S. S., and B. J. Wilson (2000): "Bertrand-Edgeworth competition, demand uncertainty, and asymmetric outcomes," Journal of economic theory, 92(1), 122-141.

Stokey, N. L. (1979): “Intertemporal Price Discrimination," The Quarterly Journal of Economics, 93(3), 355-371.

Su, X. (2007): “Intertemporal Pricing with Strategic Customer Behavior," Management Science, 53(5), 726-741.

Sweeting, A. (2012): “Dynamic Pricing Behavior in Perishable Goods Markets: Evidence from Secondary Markets for Major League Baseball Tickets," Journal of Political Economy, 120(6), 1133-1172.

Talluri, K. T., and G. J. Van Ryzin (2006): The Theory and Practice of Revenue Management, vol. 68. Springer Science \& Business Media.

Van den Berg, A., I. Bos, P. J.-J. Herings, and H. Peters (2012): “Dynamic Cournot duopoly with intertemporal capacity constraints," International Journal of Industrial Organization, 30(2), 174-192.

Weatherford, L. R., and S. E. Bodily (1992): "A taxonomy and research overview of perishable-asset revenue management: Yield management, overbooking, and pricing," Operations Research, 40(5), 831-844.

Williams, K. R. (2018): “Dynamic Airline Pricing and Seat Availability," Cowles Foundation Discussion Paper, No 2103R. 


\section{A Appendix}

\section{Proof of Lemma 1:}

Proof. Suppose not, so some firm is charging a price not equal to the market-clearing price and trade takes place at that price.

Suppose that some firm is charging a price strictly below the market-clearing price with strictly positive probability. Let $p_{L}$ be the lowest price offered by any firm. Clearly any firm offering to sell at $p_{L}$ sells all of its capacity. The firm either sells all of its capacity in Stage 1, or its sales in Stage 1 are equal to $D_{1}\left(p_{L}\right)$ and then in Stage 2 the demand for its product is $D_{2}\left(p_{L}\right)$. And since $p_{L}$ is below the market clearing price, it follows that $D_{1}\left(p_{L}\right)+$ $D_{2}\left(p_{L}\right)$ strictly exceeds the firms' total capacity, which in turn clearly exceeds the capacity of the firm charging $p_{L}$. But if the firm sells all of its capacity, then there must exist a price strictly higher than $p_{L}$ at which the firm also sells all of its capacity and the firm earns strictly higher profits, which is a contradiction.

Now suppose instead that some firm sets a price strictly greater than the marketclearing price with strictly positive probability. Let $p_{H}$ be the highest price offered in equilibrium with positive probability, which implies that at least one firm offering to sell at $p_{H}$ does not sell all of its capacity. If two or more firms set a price of $p_{H}$ with strictly positive probability, then a firm that does not sell off of its capacity can decrease its price to $p_{H}-\epsilon$ and strictly increase its sales and profits, which is a contradiction.

If at most one firm charges the price $p_{H}$ with strictly positive probability, then the firm charging $p_{H}$ earns a profit equal to $p_{H} R D_{1}\left(p_{H} ; \mathbf{p}^{-i}, \mathbf{K}^{-i}\right)+D_{2}\left(p_{H}\right)$, where $\mathbf{p}^{-i}$ and $\mathbf{K}^{-i}$ are the other firms' prices and capacities, if it's sales are positive in Stage 1; in this case every other firm sells all of its capacity in Stage 1 so the firm is the only seller in Stage 2. And the firm charging $p_{H}$ earns a profit equal to $p_{H} R D_{2}\left(p_{H} ; \mathbf{p}^{-i}, \mathbf{K}_{2}^{-i}\right)$, where $\mathbf{K}_{2}^{-i}$ is the other firms' remaining capacity at the start of Stage 2, if it has zero sales in Stage 1.

Clearly the firm will not sell all of its capacity in either case, because $p_{H}$ exceeds the 
market-clearing price and, as we have shown above, other firms are all setting prices at or above the market-clearing price, so total consumption must be less than available capacity.

Consider the profits of the firm charging $p_{H}$ under the assumption that the firms rivals are playing pure strategies. Under the efficient rationing rule, if the firm charging $p_{H}$ has positive sales in Stage 1, then the derivative of profit with respect to price is $R D_{1}\left(p_{H} ; \mathbf{p}^{-i}, \mathbf{K}^{-i}\right)+p_{H} D_{1}^{\prime}\left(p_{H}\right)+D_{2}\left(p_{H}\right)+p_{H} D_{2}^{\prime}\left(p_{H}\right)$, which is negative because $R D_{1}\left(p ; \mathbf{p}^{-i}, \mathbf{K}^{-i}\right)<$ $D_{1}(p)$, because $p D_{1}^{\prime}(p)+D_{1}(p)<0$, and because $p D_{2}^{\prime}(p)+D_{2}(p)<0$. The second and third statements are true because, by Assumption 1, $D_{1}\left(p_{H}\right)+D_{2}\left(p_{H}\right)$ is less than the revenuemaximizing output (marginal revenue is positive). So, lowering price below $p_{H}$ increases profit, which is a contradiction. Under the efficient rationing rule, if the firm charging $p_{H}$ has zero sales in Stage 1, then the derivative of profit with respect to price is $D_{2}\left(p_{H}\right)+p_{H} D_{2}^{\prime}\left(p_{H}\right)$, which is negative because, by Assumption $1, D_{2}\left(p_{H}\right)$ is less than the revenue-maximizing output (marginal revenue is positive). So, lowering price below $p_{H}$ increases profit, which is a contradiction. However, rival firms may be playing mixed strategies, so the firm's expected profits is a weighted average of the profit functions above, all of which are higher at a lower price, so we have a contradiction.

Under the proportional rationing rule, if the firm charging $p_{H}$ has positive sales in Stage 1, then the derivative of profit with respect to Firm $i$ 's price is

$$
\begin{aligned}
R D_{1}\left(p ; \mathbf{p}^{-i}, \mathbf{K}^{-i}\right)+p_{H} R D_{1}^{\prime}\left(p_{H} ; \mathbf{p}^{-i}, \mathbf{K}^{-i}\right)+p_{H} D_{2}\left(p_{H}\right)+D_{2}^{\prime}\left(p_{H}\right)= \\
\left(p_{H} D_{1}^{\prime}\left(p_{H}\right)+D_{1}\left(p_{h}\right)\right)\left[1-\sum_{j \neq i} \frac{K^{j}}{D_{2}\left(p^{j}\right)}\right]+\left(p D_{2}^{\prime}(p)+D_{2}(p)\right)
\end{aligned}
$$

which is negative because $p_{H} D_{1}^{\prime}\left(p_{H}\right)+D_{1}\left(p_{H}\right)<0$ and $p_{H} D_{2}^{\prime}\left(p_{H}\right)+D_{2}\left(p_{H}\right)<0$. These are both true because, by Assumption 1, $D_{1}\left(p_{H}\right)+D_{2}\left(p_{H}\right)$ is less than the revenue-maximizing output. So lowering price below $p_{H}$ increases profit, which is a contradiction. Under the proportional rationing rule, if the firm charging $p_{H}$ has zero sales in Stage 1 , then the 
derivative of profit with respect to Firm i's price is

$$
\begin{aligned}
& R D_{2}\left(p ; \mathbf{p}^{-i}, \mathbf{K}_{1}^{-i}\right)+p_{H} R D_{2}^{\prime}\left(p_{H} ; \mathbf{p}^{-i}, \mathbf{K}_{1}^{-i}\right)= \\
& \quad\left(p_{H} D_{1}^{\prime}\left(p_{H}\right)+D_{1}\left(p_{h}\right)\right)\left[1-\sum_{j \neq i} \frac{K^{j}}{D_{2}\left(p^{j}\right)}\right]+\left(p D_{2}^{\prime}(p)+D_{2}(p)\right)
\end{aligned}
$$

which is negative because $p_{H} D_{1}^{\prime}\left(p_{H}\right)+D_{1}\left(p_{H}\right)<0$ and $p_{H} D_{2}^{\prime}\left(p_{H}\right)+D_{2}\left(p_{H}\right)<0$. This is true because $D_{1}\left(p_{H}\right)+D_{2}\left(p_{H}\right)$ is less than the revenue-maximizing output. So lowering price below $p_{H}$ increases profit, which is a contradiction. Again, if rivals are playing mixed strategies than the firm's expected profit is a weighted average of the pure-strategy profit functions above, all of which are higher at a price below $p_{H}$, so we have a contradiction.

\section{Proof of Lemma 2:}

Proof. Suppose not, so some firm is charging a price not equal to the market-clearing price in Stage 2.

Suppose that some firm is charging a price strictly below the market-clearing price with positive probability. Let $p_{L}$ be the lowest price offered in equilibrium with positive probability. Clearly any firm offering to sell at $p_{L}$ sells all of its capacity (because $p_{L}$ is below the market clearing price), but then there must exist a strictly higher price at which the same firm sells all of its capacity and earns strictly higher profits, which is a contradiction.

Now suppose instead that some firm charges a price strictly above the market-clearing price with positive probability. Let $p_{H}$ be the highest price offered in equilibrium with positive probability. Clearly at least one firm offering to sell at $p_{H}$ does not sell all of its capacity (because $p_{H}$ is above the market clearing price). If two or more firms charge $p_{H}$ with strictly positive probability, then at least one of the firms does not sell all of its capacity, and that firm can decrease its price to $p_{H}-\epsilon$ and strictly increase its sales and profits, which is a contradiction. If zero or one firm is charging the price $p_{H}$ with strictly positive probability, and if other firms are playing pure strategies, then a firm charging $p_{H}$ 
earns profits equal to $p R D_{2}\left(p ; \mathbf{p}^{-i}, \mathbf{q}^{-i}\right)$, where $\mathbf{p}^{-i}$ and $\mathbf{q}^{-i}$ are the other firms' prices and remaining capacities.

Under the efficient rationing rule, the derivative of profit with respect to price is $R D_{2}\left(p ; \mathbf{p}^{-i}, \mathbf{q}^{-i}\right)+p D_{2}^{\prime}(p)$, which is negative because $R D_{2}\left(p ; \mathbf{p}^{-i}, \mathbf{q}^{-i}\right)<D_{2}(p)$ and because $p D_{2}^{\prime}(p)+D_{2}(p)<0$. This is true because, by Assumptions 1 and 2, $D_{2}(p)$ is less than the revenue-maximizing output. So, lowering price below $p_{H}$ increases profit, which is a contradiction.

Under the proportional rationing rule, the derivative of profit with respect to Firm $i^{\prime}$ s price is $R D_{2}\left(p ; \mathbf{p}^{-i}, \mathbf{q}^{-i}\right)+p R D_{2}^{\prime}\left(p ; \mathbf{p}^{-i}, \mathbf{q}^{-i}\right)=\left(p D_{2}^{\prime}(p)+D_{2}(p)\right)\left[1-\sum_{j \neq i} \frac{q^{j}}{D_{2}\left(p^{j}\right)}\right]$, which is negative because $p D_{2}^{\prime}(p)+D_{2}(p)<0$. This is true because $D_{2}(p)$ is less than the revenuemaximizing output. So lowering price below $p_{H}$ increases profit, which is a contradiction.

Finally, because the firm charging $p_{H}$ earn high profits at a lower price regardless of what prices the rivals set, the argument above also holds when rivals are playing mixed strategies.

\section{Proof of Proposition 1:}

Let $p_{L}=\min _{i} p_{1}^{i}$ denote the lowest equilibrium price offered in Stage 1. And recall that by Lemma 2, under Assumption 1 and 2 all firms with positive remaining capacity in the Stage 2 charge the market-clearing price. The proof of the proposition proceeds as a series of six claims.

1) In any pure strategy equilibrium of the pricing subgame that has positive sales in both stages, $p_{L} \leq p_{2}$

If a pure strategy equilibrium exists in which $p_{L} \geq p_{2}$, then all consumers who arrive in Stage 1 must be waiting to purchase until Stage 2. So sales are zero at $p_{L}$, which is a contradiction. 
2) In any pure strategy equilibrium of the pricing subgame, if $p_{L}$ is offered by two or more firms in Stage 1 , and if sales at $p_{L}$ are strictly positive, then $p_{L}=p_{2}$.

Suppose not. Then $p_{L}<p_{2}$ (by Claim 1), and $p_{L}$ is offered by two or more firms. Let Firm $i$ be one of these firms. Then Firm $i$ 's profit can be written as $p_{L} x_{i}+P_{2}\left(K^{i}-x_{i}\right)$, where $x_{i}=\min \left\{R D_{1}\left(p_{L} ; p_{L}, \sum_{j \neq i \mid p^{j}=p_{L}} K^{j}\right), K^{i}\right\}$ is Firm $i^{\prime}$ s sales at $p_{L}$.

If Firm $i$ deviates to a slightly higher price $p_{L}+\epsilon$, its profit is

$$
\begin{aligned}
\left(p_{L}+\epsilon\right) \min \left\{R D_{1}\left(p_{L}+\epsilon ; p_{L}, \sum_{j \neq i \mid p^{j}=p_{L}} K^{j}\right), K^{i}\right\} & \\
& +\hat{P}_{2}(\cdot) \max \left\{K^{i}-R D_{1}\left(p_{L}+\epsilon ; p_{L}, \sum_{j \neq i \mid p^{j}=p_{L}} K^{j}\right), 0\right\},
\end{aligned}
$$

where $\hat{P}_{2}(\cdot)$ is the market clearing price in period 2, which is a continuous and decreasing function of the total capacity remaining after Stage 1.

If $x^{i}=K^{i}$, then Firm $i^{\prime}$ s profit is clearly higher since $p_{L}+\epsilon>p_{L}$ and $\hat{P}_{2}(\cdot)>p_{L}$, so all of Firm $i$ 's sales are at a higher price, and its sales volume doesn't change.

If, on the other hand, $x^{i}<K^{i}$ and $R D_{1}\left(p_{L} ; p_{L}, \sum_{j \neq i \mid p j=p_{L}} K^{j}\right)<K^{i}$, then the same deviation is still profitable for Firm $i$ because

$$
\lim _{\epsilon \rightarrow 0} R D_{1}^{i}\left(p_{L}+\epsilon ; p_{L}, \sum_{j \neq i \mid p^{j}=p_{L}} K^{j}\right) \leq R D_{1}^{i}\left(p_{L} ; p_{L}, \sum_{j \neq i \mid p^{j}=p_{L}} K^{j}\right)<K^{i}
$$

since $R D$ is decreasing in price (for either rationing rule), and so the limit of (9) as $\epsilon$ goes to 0 is

$$
p_{L} \lim _{p \downarrow p_{L}} R D_{1}^{i}\left(p ; p_{L}, \sum_{j \neq i \mid p^{j}=p_{L}} K^{j}\right)+P_{2}\left(K^{i}-\lim _{p \downarrow p_{L}} R D_{1}^{i}\left(p ; p_{L}, \sum_{j \neq i \mid p^{j}=p_{L}} K^{j}\right)\right) .
$$

Profits are higher because the firm sells more units at $p_{2}$ and fewer units at $p_{L}$ and $p_{2}>p_{L}$. A deviation is profitable, which is a contradiction. 
3) If $p_{L}=p_{2}$, then the equilibrium is a uniform-price equilibrium.

Suppose not, so some Firm $j$ sets a price $p^{j}>p_{L}=p_{2}$ in Stage 1. Because consumers can wait, it follows that Firm $j$ 's sales are zero, so the equilibrium is a uniform-price equilibrium.

4) There exists, at most, one uniform-price equilibrium of the pricing subgame (the total sales and the transaction price is unique).

Given the capacity, the price and volume of sales in a uniform-price equilibrium are uniquely defined, because only one price satisfies $D_{1}(p)+D_{2}(p)=\sum_{i} K^{i}$.

5) All pure-strategy subgame perfect equilibria are either a uniform-price equilibrium or an asymmetric price equilibrium, and either a uniform-price equilibrium or an asymmetric price equilibrium, exists, but not both.

As above, consider the unique candidate uniform-price equilibrium. Suppose this equilibrium does not exist. Then it must be that either deviating in Stage 1 is profitable. But deviating to a higher price in Stage 1 is never profitable. Consumers prefer to wait and buy at the market clearing price in Stage 2. So deviating to a lower price must be profitable.

If deviating from the uniform-price to a lower price in Stage 1 is profitable for some firm, then it is clearly also profitable for the firm that has the largest capacity. Let $i$ denote the firm with the largest capacity; let $p_{1}^{i}$ denote the firm's profit-maximizing deviation in Stage 1 ; and let $\hat{p}_{2}$ denote the resulting second-period market-clearing price.

Then it follows that $p_{1}^{i}$ and $\hat{p}_{2}$ must define an asymmetric-price equilibrium. Firm $i$ sells in both periods (otherwise the deviation isn't profitable) so all other firms muse sell only in Stage 2. Clearly Firm $i$ has no incentive to deviate since by construction $p_{1}^{i}$ is its best response to the other firms' strategies. And if any other firm could increase its profits by charging a price less than $p_{1}^{i}$, then it follows that Firm $i$ could also increase its profit 
by deviating to that same price (because Firm $i$ has more capacity), in which case $p_{1}^{i}$ is not Firm $i$ 's profit-maximizing price, which is a contradiction.

Similarly, if an asymmetric price equilibrium exists, then $p_{1}^{i}$ must be the best response for Firm $i$ to other firms prices, even if they were all charging $p_{2}$ in Stage 1. So a uniformprice equilibrium does not exist.

\section{6) There exist at most $n$ asymmetric-price equilibria.}

We show that there exists, at most, one asymmetric-price equilibrium in which Firm $i$ is the low-priced firm in period one (or, more strictly speaking, such equilibria differ only in the prices of firms with zero sales).

In an asymmetric-price equilibrium, if Firm $i$ is the low-price firm, then it is the only firm with positive sales in Stage 1. Let $p$ denote Firm $i$ 's equilibrium price. As in Claim 5 let $p_{1}^{i}$ denote Firm $i$ 's best response when rival firm's are charging the unique uniform-price equilibrium price, which is the same as its optimal price when rivals are setting the market clearing price in Stage 2.

However, if $p>p_{1}^{i}$, then Firm $i$ can profitably deviate to $p_{1}^{i}$ because regardless of what price it sets, its rivals are selling at the market clearing price in Stage 2. And, if $p<p_{1}^{i}$ then because $\pi(p)$ is concave and maximized at $p_{1}^{i}$, it follows that Firm $i$ is strictly better off increasing its price. So, $p$ cannot be an asymmetric-price equilibrium price unless $p=p_{1}^{i}$.

Therefore, the only one asymmetric-price equilibrium that can exist in which Firm $i$ is the low-price firm in the first period and that equilibrium is given by (3) and (5). Since there are $n$ firms there are at most $n$ asymmetric-price equilibria.

\section{Proof of Proposition 2:}

Proof. Let $K^{i}$ denote each firm's capacity, and let $\tilde{p}$ denote the unique uniform price defined by $D_{\text {tot }}(\tilde{p})=D_{1}(\tilde{p})+D_{2}(\tilde{p})=\sum_{i=1}^{n} K^{i}$.

Consider a deviation to a lower price in the first pricing period. If $D_{1}(\tilde{p}) \geq \max _{i} K^{i}$, 
then a deviation to a lower price is not profitable, because any firm that cuts its price in Stage 1 will sell all of its capacity at the lower deviation price and hence earn strictly lower profits.

If $D_{1}(\tilde{p})<\max _{i} K^{i}$, then for any Firm $i$ such that $K^{i} \leq D_{1}(\tilde{p})$, a deviation to a lower price is not profitable by the same argument. When $K^{i}>D_{1}(\tilde{p})$, then a deviation to a lower price could increase the market-clearing price in period 2, and could increase the firms profits, but only if demand is becoming less elastic over time so firms jointly prefer to set prices that increase over time.

Let Firm $i$ be the deviating firm, and let $p_{2}(\cdot)$ denote the second-period market-clearing price as a function of remaining capacity. Firm $i^{\prime}$ s problem is to choose a price $p^{i}<\tilde{p}$, or equivalently, a quantity $q^{i}=D_{1}\left(p^{i}\right)$ to maximize

$$
\hat{\pi}^{i}\left(q^{i} ; \tilde{p}, \mathbf{K}\right)=q^{i} p_{1}\left(q^{i}\right)+P_{2}\left(\sum_{i=1}^{n} K^{i}-q^{i}\right)\left(K^{i}-q^{i}\right)
$$

subject to $q^{i} \in\left(D_{1}(\tilde{p}), K^{i}\right]$ - higher output levels are not feasible, and lower output levels are inconsistent with a lower first period price. The first-order condition is

$$
\frac{d \hat{\pi}\left(q^{i} ; \tilde{p}, \mathbf{K}\right)}{d q}=P_{1}\left(q^{i}\right)+q^{i} P_{1}^{\prime}\left(q^{i}\right)-P_{2}\left(\sum_{i=1}^{n} K^{i}-q^{i}\right)-P_{2}^{\prime}\left(\sum_{i=1}^{n} K^{i}-q^{i}\right)\left(K^{i}-q^{i}\right)=0
$$

or

$$
\begin{aligned}
\frac{d \hat{\pi}\left(q^{i} ; \tilde{p}, \mathbf{K}\right)}{d q}= & P_{1}\left(q^{i}\right)\left(1+\frac{1}{\eta_{1}\left(P_{1}\left(q^{i}\right)\right)}\right) \\
& -P_{2}\left(\sum_{i=1}^{n} K^{i}-q^{i}\right)\left(1+\frac{1}{\eta_{2}\left(P_{2}\left(\sum_{i=1}^{n} K^{i}-q^{i}\right)\right)} \frac{K^{i}-q^{i}}{\sum_{i=1}^{n} K^{i}-q^{i}}\right)=0
\end{aligned}
$$

Clearly, the objective function, equation (10), is concave, so (12) implies that a deviation to a lower price is profitable if and only if $\lim _{q \downarrow D_{1}(\tilde{p})} \frac{d \hat{\pi}(q ; \tilde{p}, \mathbf{K})}{d q}>0$, or equivalently, 
$\lim _{p \uparrow \tilde{p}} \frac{d \hat{\pi}\left(D_{1}(p) ; \tilde{p}, \mathbf{K}\right)}{d q}>0$. But clearly

$$
\begin{aligned}
\lim _{p \uparrow \tilde{p}} \frac{d \hat{\pi}\left(D_{1}(p) ; \tilde{p}, \mathbf{K}\right)}{d q} & <P_{1}\left(D_{1}(\tilde{p})\right)\left(1+\frac{1}{\eta_{1}\left(P_{1}\left(D_{1}(\tilde{p})\right)\right.}\right) \\
& -P_{2}\left(\sum_{i=1}^{n} K^{i}-D_{1}(\tilde{p})\right)\left(1+\frac{1}{\eta_{2}\left(P_{2}\left(\sum_{i=1}^{n} K^{i}-D_{1}(\tilde{p})\right)\right)} \frac{K^{i}}{\sum_{i=1}^{n} K^{i}}\right)
\end{aligned}
$$

because $\frac{K^{i}-q}{\left(\sum_{i=1}^{n} K^{i}-q\right)}<\frac{K^{i}}{\sum_{i=1}^{n} K^{i}}$. Since $P_{1}\left(D_{1}(\tilde{p})\right)=P_{2}\left(\sum_{i=1}^{n} K^{i}-D_{1}(\tilde{p})\right)=\tilde{p}$, it follows that a deviation to a lower price is not profitable if

$$
\frac{1}{\eta_{1}\left(P_{1}\left(D_{1}(\tilde{p})\right)\right)}-\frac{1}{\eta_{2}\left(P_{2}\left(\sum_{i=1}^{n} K^{i}-D_{1}(\tilde{p})\right)\right)} \frac{K^{i}}{\sum_{i=1}^{n} K^{i}}<0 \Longleftrightarrow \frac{\eta_{2}(\tilde{p})}{\eta_{1}(\tilde{p})}>\frac{K^{i}}{\sum_{i=1}^{n} K^{i}}
$$

or, equivalently, if Assumption 3 holds. If demand in the second period is too much more inelastic, a deviation will be profitable.

Now consider a deviation to a higher price. If $D_{1}(\tilde{p})<\sum_{j \neq i} K^{j}$, for all $i$, then no firm's deviation to a higher price can have any effect on first or second period sales. The firm's that don't deviate can meet all of the demand at the price $\tilde{p}$.

If on the other hand $D_{1}(\tilde{p})>\sum_{j \neq i} K^{j}$, for some $i$, then some firm or firms can deviate to a higher price and have positive sales, however even a monopolist would not find such a deviation profitable when demand is becoming less elastic over time, so no firm will deviate to a higher price.

\section{Proof of Proposition 3:}

Proof. Under Assumptions 1, 2 and 4, if a subgame perfect equilibrium exists in which every firm chooses $K^{*}$ units of capacity, then, by Proposition 2 , the unique subgame perfect equilibrium of the pricing subgame is a uniform-price equilibrium. Moreover, for all firm capacities in a neighborhood of $K^{*}$, Assumption 4 and Proposition 2 imply that the unique subgame perfect equilibrium of the pricing subgame is a uniform-price equilibrium, so 
the first-stage profit function for Firm $i$ can be written as

$$
\Pi^{u}\left(K^{i} ; K^{-i}\right)=\left(P_{t o t}\left(\sum_{j} K^{j}\right)-c\right) K^{i},
$$

where $K^{-i}$ is the capacity of the other firms.

Firm $i^{\prime}$ s capacity, $K^{i}$, maximizes Firm $i^{\prime}$ s profits only if $K^{i}=K^{*}$ is the solution to

$$
\frac{\partial \Pi^{u}\left(K^{i} ; K^{*}\right)}{\partial K^{i}}=P_{t o t}\left((n-1) K^{*}+K^{i}\right)-c+P_{t o t}^{\prime}\left((n-1) K^{*}+K^{i}\right) K^{i}=0,
$$

which is concave and has a unique solution, $K^{i}\left(K^{*}\right)$, which is decreasing in $K^{*}$. So, (15) uniquely defines a symmetric solution $K^{*}$, and it is easy to see that $K^{*}$ must be exactly equal to the Cournot quantity associated with $n$ firms, production $\operatorname{cost} c$, and demand $D_{\text {tot }}(p)$. So we have shown that $K^{i}=K^{*}$ is local best response. Next, we show that $K^{i}=K^{*}$ is the global best response when rival firms choose $K^{*}$.

Suppose that $K^{i}<K^{*}$. If a uniform price equilibrium exists when Firm $i$ chooses $K^{i}$ and other firms choose $K^{*}$, then Firm $i$ 's profits are given by (14), and so Firm $i^{\prime}$ s profits at $K^{i}$ are strictly lower than at $K^{*}$.

If a uniform-price equilibrium does not exist, then by Proposition 1 an asymmetricprice equilibrium must exist. Under Assumption 4, Firm $i$ cannot profit by deviating from the uniform-price equilibrium even if its capacity is $K^{*}$, so Firm $i$ is not the low-priced firm in the first period. The only asymmetric-price equilibrium that can exist is one in which one of Firm $i$ 's rivals is the firm that sells at the low price in the first period. There are $n-1$ such equilibria because any of the $n-1$ firms with capacity $K^{*}$ could set the low price in the first period.

Firm $i$ 's profit in all of these asymmetric-price equilibria is

$$
\Pi^{a}\left(K^{i} ; K^{*}\right)=\left[P_{2}\left((n-1) K^{*}+K^{i}-D_{1}\left(p_{1}\right)\right)-c\right] K^{i},
$$


where $p_{1}$ is the price charged in the first period, and so $p_{1}$ maximizes

$$
D_{1}\left(p_{1}\right) p_{1}+P_{2}\left((n-1) K^{*}+K^{i}-D_{1}\left(p_{1}\right)\right)\left(K^{*}-D_{1}\left(p_{1}\right)\right)
$$

Firm $i^{\prime}$ s first order-condition is

$$
P_{2}^{\prime}\left((n-1) K^{*}+K^{i}-D_{1}\left(p_{1}\right)\right)\left(1-D_{1}^{\prime}\left(p_{1}\right) \frac{d p_{1}}{d K^{i}}\right)+P_{2}\left((n-1) K^{*}+K^{i}-D_{1}\left(p_{1}\right)\right)-c=0 .
$$

Because $p_{1}<p_{2}, D\left(p_{1}\right)$ is greater than first-period sales at the uniform price. This implies that $n-1$ firms are each selling less than $K^{*}-D(\tilde{p}) / n$ in period 2, where $\tilde{p}$ is the uniform price. In this case, ignoring the impact of $K^{i}$ on $p_{1}$, Firm $i^{\prime}$ s best response is greater than $K^{*}-D(\tilde{p}) / n$, which implies that $K^{i}>K^{*}$, which is a contradiction. And, as $K^{i}$ increases, the optimal first-period price falls $\left(d p_{1} / d K^{i}<0\right)$. Thus, ignoring the impact of $K^{i}$ on $p_{1}$ does not alter the result. Deviating to a lower $K^{i}$ is still not profitable.

Now suppose that $K^{i}>K^{*}$. Again, the equilibrum of the pricing subgame may be an asymmetric-price equilibrium or a uniform-price equilibrium. If it is a uniform-price equilibrium, then by the same argument, profits are strictly lower.

If it is an asymmetric-price equilibrium, then it must be an asymmetric-price equilibrium in which Firm $i$ sets a low price in the first period. This is because an asymmetric-price equilibrium exists only if a firm wants to deviate from the uniform-price equilibrium, and equation (13) tells us that a firm wants to deviate only if $\eta_{2}(p) / \eta_{1}(p)$ exceeds its share of capacity. But by Assumption 4, this happens only if the capacity share exceeds $1 / n$ and only Firm $i$ 's share of capacity exceeds $1 / n$.

So, if Firm $i$ deviates to $K^{i}>K^{*}$, then its profit must be

$$
\max _{p_{1}} D_{1}\left(p_{1}\right) p_{1}+P_{2}\left((n-1) K^{*}+K^{i}-D_{1}\left(p_{1}\right)\right)\left(K^{i}-D_{1}\left(p_{1}\right)\right)
$$


Rewriting this as a function of quantity yields

$$
\max _{q_{1}} P_{1}\left(q_{1}\right) q_{1}+P_{2}\left((n-1) K^{*}+K^{i}-q_{1}\right)\left(K^{i}-q_{1}\right)
$$

Thus, the firm's profit in stage one is

$$
\max _{q_{1}} P_{1}\left(q_{1}\right) q_{1}+P_{2}\left((n-1) K^{*}+K^{i}-q_{1}\right)\left(K^{i}-q_{1}\right)-c K^{i}
$$

and its maximized profit in stage one is

$$
\max _{q_{1}, K_{1}} P_{1}\left(q_{1}\right) q_{1}+P_{2}\left((n-1) K^{*}+K^{i}-q_{1}\right)\left(K^{i}-q_{1}\right)-c K^{i}
$$

which we can rewrite using a change of variables $\left(q_{2}=K^{i}-q_{1}\right)$ as

$$
\max _{q_{1}, q_{2}} P_{1}\left(q_{1}\right) q_{1}-c q_{1}+P_{2}\left((n-1) K^{*}+q_{2}\right) q_{2}-c q_{2}
$$

Therefore, $q_{1}$ is the first-period monopoly output. and $q_{2}$ is the second-period best response to $(n-1) K^{*}$. But this is not an equilibrium unless $p_{1}<p_{2}$, or equivalently the Lerner index in the first period is smaller than the Lerner index in period 2, or

$$
\begin{aligned}
& \frac{P_{1}^{\prime}\left(q_{1}\right) q_{1}}{P_{1}\left(q_{1}\right)}<\frac{P_{2}^{\prime}\left((n-1) K^{*}+q_{2}\right) q_{2}}{P_{2}\left((n-1) K^{*}+q_{2}\right)} \\
& \frac{1}{\left|\eta_{1}\left(p_{1}\right)\right|}<\frac{1}{\left|\eta_{2}\left(p_{2}\right)\right|} \frac{q_{2}}{(n-1) K^{*}+q_{2}}
\end{aligned}
$$

or

$$
\frac{\eta_{2}\left(p_{2}\right)}{\eta_{1}\left(p_{1}\right)}<\frac{q_{2}}{(n-1) K^{*}+q_{2}}
$$

which violates Assumption 4 because $q_{2}<K^{*}$. So, this is a contradiction. Hence there exists no profitable deviation for any firm. 


\section{Proof of Proposition 4:}

This follows immediately from Proposition 1, which shows that a pure strategy equilibrium exists and that any pure strategy equilibrium must be a uniform-price equilibrium or an asymmetric price equilibrium in which the Stage 1 price is strictly lower than the Stage 2 price. But if the elasticity of demand is increasing, an asymmetric price equilibrium cannot exist. The firm selling in Stage 1 prefers to sell all of its capacity at the market clearing price is stage 2 .

\section{Proof of Proposition 5:}

By Proposition 4 all transactions take place at the same price, and by Lemma 1 this implies that firms must set the Cournot capacities as if there were one combined sales period.

\section{Proof of Proposition 6:}

Proof. Let $k_{t}^{i}$ denote the inventory control for Firm $i$ in period $t$.

Consider an equilibrium in which, on the equilibrium path, firms choose capacity equal to the sum of the Cournot capacity in each period, $q_{1}^{C}+q_{2}^{C}$, and then set the Cournot price, $p_{t}^{C}$ in each period, and set $k_{t}^{i}=q_{t}^{C}$ in each period, so inventory controls equal to the Cournot output in each period.

Off of the equilibrium path, firms set the market-clearing price in the last period. In the first period, given capacity, firms set the price $p_{1}^{i}$ and the inventory control $k_{1}^{i}$ which correspond to the Cournot price and quantity. That is, firms allocate their capacity across periods one and two as if they were playing a Cournot game in each period with a capacity constraint across the two periods. The set price equal to the Cournot price associated with the firms' allocations and the set the inventory control equal to that allocation. More formally, firms equate the marginal revenue of output across the two periods.

Clearly no deviation is profitable in the final period. That is, in every subgame firms set the market clearing price and set a non-binding inventory control. This is because 
Lemma 2 holds, so any second-period price not equal to the market-clearing prices are not sequentially optimal - the presence of inventory controls does not change this result.

Now consider a deviation by Firm $i$ to a lower price in the first selling period. Decreasing demand elasticity implies that $p_{1}^{C}<p_{2}^{C}$, so a small decrease in its first-period price discontinuously increases Firm $i$ 's first-period sales, decreases Firm $i$ 's second-period sales, and decreases Firm $i$ 's profits. More generally, if Firm $i$ had a profitable deviation to a lower price in period one, then that price would define an asymmetric price equilibrium, but by Proposition 2 an asymmetric-price equilibrium does not exist. So no deviation to a lower price is profitable.

Suppose, instead, that Firm $i$ deviates to a higher price in the first period. Under the efficient rationing rule, the residual demand function facing the deviating firm is $R D_{1}^{i}\left(p^{i} ; p-i_{1}, q-i_{1}\right)=D_{1}(p)-(n-1) q_{1}^{C}$. This is because rival firms' inventory controls, $k_{1}^{j}=q_{1}^{C}$ (if any firm deviate in stage zero, then $k_{1}^{j}$ equals then adjust Cournot output given the new capacity constrain.

Since the shadow cost of capacity is $c$ on the equilibrium path (and, more generally, is equalized across both periods), Firm $i^{\prime}$ s first-period profit function is $\left(D_{1}\left(p^{i}\right)-(n-\right.$ 1) $\left.q_{1}^{C}\right)\left(p^{i}-c\right)$ or, equivalently, $\left(p_{1}\left((n-1) q_{1}^{C}+q^{i}\right)-c\right) q^{i}$ where $p_{1}$ is the first period inverse demand function. Thus, the optimal price deviation is given by the first-order condition, which is

$$
P_{1}^{\prime}\left((n-1) q_{1}^{C}+q\right) q+P_{1}\left((n-1) q_{1}^{C}+q\right)=c
$$

But this implies that $q=q_{1}^{C}$ and that the optimal price and quantity is the first-period Cournot output (or, more generally, is the output that equalizes the marginal revenue across the two periods), so no deviation to a higher price is profitable.

Under proportional rationing, the deviating firm's residual demand function is

$$
R D_{1}^{i}\left(p^{i} ; p_{1}^{C}, q_{1}^{C}\right)=D_{1}\left(p^{i}\right)\left[1-\frac{(n-1) q_{1}^{C}}{D_{1}\left(p_{1}^{C}\right)}\right]=\frac{1}{n} D_{1}\left(p^{i}\right)
$$


since $D_{1}\left(p_{1}^{C}\right)=n q_{1}^{C}$. The shadow cost of capacity is $c$ on the equilibrium path (and, more generally, is equalized across the two periods), so Firm i's first-period profit function is $\frac{1}{n} D_{1}(p)(p-c)$, or equivalently, $\left.p_{1}(n q)-c\right) q$. The first-order condition is $P_{1}(n q)+P_{1}^{\prime}(n q) q=c$, which implies that $q=q_{1}^{C}$, so no deviation to a higher price is profitable.

In stage zero, firms choose capacity expecting to equalize marginal revenue across periods 1 and 2 , and it is easy to see that $K^{i}=q_{1}^{C}+q_{2}^{C}$ is a best response to $K^{j}=q_{1}^{C}+q_{2}^{C}$ for all $j \neq i$.

\section{Cournot Model with linear demand and with and without discrimination}

First, suppose that $P(q)=a-b q$, firms have constant cost $c$, and that there are $n$ frms. Cournot output for each of $n$ firms is $(a-c) / b(n+1)$, so the total Cournot output is $(a-c) n / b(n+1)$, the Cournot price is $(a+n c) /(n+1)$, and the Cournot profit of each firm is $(a-c)^{2} / b(n+1)^{2}$.

Now consider two markets and suppose firms sell in two markets and demands are $P_{1}\left(q_{1}\right)=a_{1}-b_{1} q_{1}$ and $P_{2}\left(q_{2}\right)=a_{2}-b_{2} q_{2}$. Then if the demands are combined into one with the same price, demand is $q_{\text {tot }}=a_{1} / b_{1}+a_{2} / b_{2}-p\left(\frac{1}{b_{1}}+\frac{1}{b_{2}}\right)$ or $b_{1} b_{2} q_{t o t}=b_{2} a_{1}+b_{1} a_{2}-p\left(b_{1}+b_{2}\right)$ or $p=\frac{b_{2} a_{1}+b_{1} a_{2}}{b_{1}+b_{2}}-\frac{b_{1} b_{2}}{b_{1}+b_{2}} q_{t o t}$, so Cournot profit is $\left(\frac{b_{2} a_{1}+b_{1} a_{2}}{b_{1}+b_{2}}-c\right)^{2}\left(b_{1}+b_{2}\right) /\left(b_{1} b_{2}(n+1)^{2}\right)$ or $\left(b_{2} a_{1}+\right.$ $\left.b_{1} a_{2}-\left(b_{1}+b_{2}\right) c\right)\left(\frac{b_{2} a_{1}+b_{1} a_{2}}{b_{1}+b_{2}}-c\right) /\left(b_{1} b_{2}(n+1)^{2}\right)$ or $\left(b_{2}\left(a_{1}-c\right)+b_{1}\left(a_{2}-c\right)\right)\left(\frac{b_{2} a_{1}+b_{1} a_{2}}{b_{1}+b_{2}}-c\right) /\left(b_{1} b_{2}(n+1)^{2}\right)$

If the markets are separate and firms set different quantities (and prices) in each market, then the Cournot profits are $\left(a_{1}-c\right)^{2} /\left(b_{1}(n+1)^{2}\right)+\left(a_{2}-c\right)^{2} /\left(b_{2}(n+1)^{2}\right)$ or equivalently $\left(b_{2}\left(a_{1}-c\right)^{2}+b_{1}\left(a_{2}-c\right)^{2}\right) /\left(b_{1} b_{2}(n+1)^{2}\right)$. 